\title{
Smart Microgrid Energy Management Using a Novel Artificial Shark Optimization
}

\author{
Pawan Singh ${ }^{1}$ and Baseem Khan ${ }^{2}$ \\ ${ }^{1}$ School of Informatics, Hawassa University Institute of Technology, Hawassa, Ethiopia \\ ${ }^{2}$ School of Electrical \& Computer Engineering, Hawassa University Institute of Technology, Hawassa, Ethiopia \\ Correspondence should be addressed to Baseem Khan; baseem.khan04@gmail.com
}

Received 2 April 2017; Revised 17 June 2017; Accepted 27 June 2017; Published 8 October 2017

Academic Editor: Roberto Natella

Copyright (c) 2017 Pawan Singh and Baseem Khan. This is an open access article distributed under the Creative Commons Attribution License, which permits unrestricted use, distribution, and reproduction in any medium, provided the original work is properly cited.

\begin{abstract}
At present, renewable energy sources (RESs) integration using microgrid (MG) technology is of great importance for demand side management. Optimization of MG provides enhanced generation from RES at minimum operation cost. The microgrid optimization problem involves a large number of variables and constraints; therefore, it is complex in nature and various existing algorithms are unable to handle them efficiently. This paper proposed an artificial shark optimization (ASO) method to remove the limitation of existing algorithms for solving the economical operation problem of MG. The ASO algorithm is motivated by the sound sensing capability of sharks, which they use for hunting. Further, the intermittent nature of renewable energy sources is managed by utilizing battery energy storage (BES). BES has several benefits. However, all these benefits are limited to a certain fixed area due to the stationary nature of the BES system. The latest technologies, such as electric vehicle technologies (EVTs), provide all benefits of BES along with mobility to support the variable system demands. Therefore, in this work, EVTs incorporated grid connected smart microgrid (SMG) system is introduced. Additionally, a comparative study is provided, which shows that the ASO performs relatively better than the existing techniques.
\end{abstract}

\section{Introduction}

As the world is transforming from the conventional grid system to the smart grid system, renewable energy sources' integration has become a vital issue in the current situation. The intermittency and climate dependency of RESs make their integration more complex and difficult. A microgrid (MG) offers an efficient way to incorporate distributed RESs in large electric power systems for supplying the continually growing demand. The smart microgrid (SMG) consist of RESs (especially wind turbine (WT) and solar photovoltaic (SPV)), BESs, electric vehicle technologies (EVTs), and electrical demands. BESs and EVTs have a bidirectional battery charging system as well as automatic sensors for detecting over- or undergeneration. SMG coalesced with RESs, BESs, and EVTs is a preferable alternative to manage the increased power demand and is a supplement to the centralized smart power grids [1]. Recently, there are rising issues and concerns regarding the instability and discontinuity of RESs in the MG. Therefore, the MG central operator (MGCO) recommends the incorporation of BES in the MG for accumulating surplus power and feedback to the MG during the peak load. Further, the latest EVTs (battery electric vehicle (BEV) and plug-in hybrid vehicle (PHEV)) along with BES play a vital role to store excess power during high availability. The advantages of EVTs are their mobility and ability to supply the stored power in the energy deficient areas during peak hours. Therefore, the computation of the suitable capacity of BES, BEV, and PHEV is highly essential for an economized operation of SMG. Currently, the attention is shifted towards more efficient fuel cell technologies (FCTs), such as automotive fuel cell electric vehicle (FCEV) and stationary FC power generator (FCPG) $[2,3]$, due to their numerous advantages (less CO2 emissions, extremely less noise and vibrations). FCEV and FCPG have a lower maintenance cost, as they consist of fewer rotating parts. Additionally, FCTs do not require recharging, 
unlike BESs. FCTs are expandable and can be grouped for the required power rating [4]. FCTs decrease manufacturing, shipping, and security concerns related to MG [5].

The economical operation of SMG is one of the most significant optimization problems for MGCO, wherein the economical power output of BES, FCPG, microturbine (MT), EVTs, and RESs is computed by fulfilling all equality and inequality constraints. Various studies are performed for the economical operation of MG. Mitra [6] proposed a method to estimate the capacity of BES for removing the intermittency problem of DGs. SA is applied by Ekren and Ekren Banu [7] to optimize the capacity of DGs and minimize the total cost. Mohammadi et al. [8] applied a variation of GA to find an optimal power output as well as the cost of MG under the deregulated electricity market. Bahmani-Firouzi and Azizipanah-Abarghooee [9] developed an IBA for the economical operation of MG.

Various studies focus on the economical operation problem of MG without taking into account the effect of optimum sizing of BES. Chakraborty et al. [10] applied linear programming for the economical operation of MG and improved the BES's charge states. Sortomme and El-Sharkawi utilized PSO for the economical operation of MG [11]. Niknam et al. [12] utilized the honeybee mating optimization for the economical operation of MG, which includes PV, WT, and FC. Sharma et al. [13] presented a comparative study of metaheuristic techniques for microgrid optimization.

Nowadays, EVTs are the integral part of MG technology. Various optimization studies are performed on EVTs incorporated MG systems. Laureri et al. [14] focused on EVTs and their active participation in grid optimization by adopting power modulation under V2G mode. Bai et al. [15] designed a two-way charging system for bidirectional flow of current to convert it as a mobile energy storage system. Chen et al. [16] proposed a microgrid layout of EVT charging station, which combines with renewable energy sources and battery storage. Gunter et al. [17] presented a framework and an optimization technique to design utility coupled MG with BES, distributed generation, and PHEV chargers.

Conventional optimization techniques have a number of limitations together with continuity and derivability of the objective function. Existing methods which are based on metaheuristic search techniques $[19,20]$ can be regarded as appropriate alternatives for handling optimization problems since these metaheuristic methods provide the best global solution, handle large constraints, and are derivative-free. These methods have some shortcomings like getting stuck in local optima and take a long time to find global optima; consequently, selection of the appropriate evolutionary algorithm has great importance. In previous algorithms, the main limitation is to handle problems with a large number of variables and various constraints.

This paper proposed an artificial shark optimization (ASO) method to remove the limitation of existing algorithms for solving the economical operation problem of MG. The ASO algorithm is motivated by the sound sensing capability of sharks which they use for hunting. ASO is capable of providing extremely reasonable results of various standard functions in comparison with other renowned metaheuristic techniques. The global and local searching capabilities of ASO algorithm are far better than the former optimization method. These capabilities of ASO have encouraged the authors to utilize this algorithm to find the economical operation of SMG (EOSMG). The result obtained from ASO is compared with the results of GA, SA, and PSO to show its feasibility. The key contributions of this work are summarized as follows: (1) developing a novel ASO technique for solving EOSMG, (2) introducing V2G, G2V, and V2H technology based on SMG system, and (3) comparative analysis of developed ASO and existing methods on EOSMG and standard benchmark functions.

Section 2 describes the problem formulation of EOSMG. In Section 3, a novel optimization method called artificial shark optimization is proposed. Section 4 provides the results and discussion followed by the conclusion.

\section{Problem Formulation}

The required objective function and constraints for the formulation of an economical operation problem of SMG (EOSMG) are as follows.

Minimize total costs:

$$
\min C(X)=\sum_{t=1}^{\mathrm{NT}} c_{t}+\mathrm{OM}_{\mathrm{DG}}+\mathrm{CTCPD},
$$

where

$$
\begin{aligned}
& \mathrm{CTCPD}=\mathrm{TCPD}_{\mathrm{BES}}+\mathrm{TCPD}_{\mathrm{BEV}}+\mathrm{TCPD}_{\mathrm{PHEV}}, \\
& c_{t} \\
& =\operatorname{Cost}_{\mathrm{grid}, t}+\operatorname{Cost}_{\mathrm{DG}, t}+\operatorname{Cost}_{\mathrm{BES}, t}+\operatorname{Cost}_{\mathrm{BEV}, t} \\
& + \text { Cost }_{\mathrm{PHEV}, t}+\mathrm{SUC}_{\mathrm{FC}, t}+\mathrm{SUC}_{\mathrm{MT}, t}+\mathrm{SUC}_{\mathrm{FCEV}, t} \text {, } \\
& \text { Cost }_{\text {grid }, t}= \begin{cases}\operatorname{Bid}_{\text {grid }, t} P_{\text {grid }, t} & \text { if } P_{\text {grid, }, t}>0 \\
(1-\operatorname{tax}) B_{\text {grid }, t} P_{\text {grid }, t} & \text { if } P_{\text {grid }, t}<0 \\
0 & \text { if } P_{\text {grid }, t}=0,\end{cases} \\
& \operatorname{Cost}_{\mathrm{DG}, t} \\
& =\operatorname{Bid}_{\mathrm{MT}, t} P_{\mathrm{MT}, t} u_{\mathrm{MT}, t}+\operatorname{Bid}_{\mathrm{FC}, t} P_{\mathrm{FC}, t} u_{\mathrm{FC}, t} \\
& +\operatorname{Bid}_{\mathrm{FCEV}, t} P_{\mathrm{FCEV}, t} u_{\mathrm{FCEV}, t}+\operatorname{Bid}_{\mathrm{PV} i, t} P_{\mathrm{PV} i, t} \\
& +\operatorname{Bid}_{\mathrm{WT} i, t} P_{W T i, t}, \\
& \operatorname{SUC}_{\mathrm{FC}, t}=\operatorname{Start}_{\mathrm{FC}} * \max \left(0, u_{\mathrm{FC}, t}-u_{\mathrm{FC}, t-1}\right) \text {, } \\
& \mathrm{SUC}_{\mathrm{FCEV}, t}=\operatorname{Start}_{\mathrm{FCEV}} * \max \left(0, u_{\mathrm{FCEV}, t}-u_{\mathrm{FCEV}, t-1}\right) \text {, } \\
& \operatorname{SUC}_{\mathrm{MT}, t}=\operatorname{Start}_{\mathrm{MT}} * \max \left(0, u_{\mathrm{MT}, t}-u_{\mathrm{MT}, t-1}\right) \text {, } \\
& \mathrm{OM}_{\mathrm{DG}} \\
& =\left(\mathrm{OM}_{\mathrm{MT}}+\mathrm{OM}_{\mathrm{FC}}+\mathrm{OM}_{\mathrm{FCEV}}+\mathrm{OM}_{\mathrm{PV} i}+\mathrm{OM}_{\mathrm{WT} i}\right) \\
& \text { * NT. }
\end{aligned}
$$


The total cost of the SMG is the summation of the following costs:

(A) Operation cost of utility, BES, BEV, PHEV, and FCEV

(B) Fuel, operation, and maintenance cost of DGs

(C) Start-up costs of FC, FCEV, and MT

(D) The cumulative total cost per day (CTCPD) of batteries used in BES, BEV, and PHEV

The overall cost of batteries depends on the sum of fixed cost (FX) and maintenance cost (MC), where FX and MC are one-time purchasing cost and a variable annual maintenance cost, respectively. Therefore, the total cost, proportional to the size of batteries, is $(\mathrm{FX}+\mathrm{MC}) * C_{\max }$, where $C_{\max }$ is the maximum capacity of a battery. The study is conducted for a day and the cost of operation is computed on an hourly basis (24 values); therefore, TCPD is modeled in €ct/day. Let IR and LT be the rate of interest for funding the installed battery and its lifetime, respectively; then, the TCPDs in €ct/day has been calculated as follows [18]:

$$
\begin{aligned}
& \mathrm{TCPD}_{\mathrm{BES}} \\
& =\frac{C_{\mathrm{BES}, \text { max }}}{365}\left(\frac{\mathrm{IR}(1+\mathrm{IR})^{\mathrm{LT}}}{(1+\mathrm{IR})^{\mathrm{LT}}-1} \mathrm{FC}_{\mathrm{BES}}+\mathrm{MC}_{\mathrm{BES}}\right), \\
& \mathrm{TCPD}_{\mathrm{BEV}} \\
& =\frac{\mathrm{C}_{\mathrm{BEV}, \text { max }}}{365}\left(\frac{\mathrm{IR}(1+\mathrm{IR})^{\mathrm{LT}}}{(1+\mathrm{IR})^{\mathrm{LT}}-1} \mathrm{FC}_{\mathrm{BEV}}+\mathrm{MC}_{\mathrm{BEV}}\right), \\
& \mathrm{TCPD}_{\mathrm{PHEV}} \\
& =\frac{\mathrm{C}_{\mathrm{PHEV}, \text { max }}}{365}\left(\frac{\mathrm{IR}(1+\mathrm{IR})^{\mathrm{LT}}}{(1+\mathrm{IR})^{\mathrm{LT}}-1} \mathrm{FC}_{\mathrm{PHEV}}+\mathrm{MC}_{\mathrm{PHEV}}\right) .
\end{aligned}
$$

The proposed operation cost minimization problem handles the constraints as presented in Table 1 .

\section{Artificial Shark Optimization Algorithm}

Metaheuristic optimization algorithms are best suited to solve the complex engineering problems as they depend on simple and easily implantable concepts, bypass local optima, and do not need gradient data.

3.1. Motivation. Nature finds solutions in a better manner than humans. Modeling biological, physical, or behavioral phenomena of natural objects provides better capabilities to solve optimization problems. Such optimization methods are categorized as nature inspired metaheuristic algorithms. The great hunting capabilities of sharks have become a motivation to propose this optimization algorithm. Sharks are great swimmers with fantastic sudden and smooth turning capabilities. Sharks swim in the ocean in groups and search for food by identifying the proper location of prey. Sharks have strong sensing potential; they can hear their prey in the water even from approximately 3000 feet away [21]. This makes sharks a deadly hunter that survived for millions of years even before the dinosaurs.

The sound of the prey helps sharks to locate the appropriate position of their prey. The shark receives a fraction of

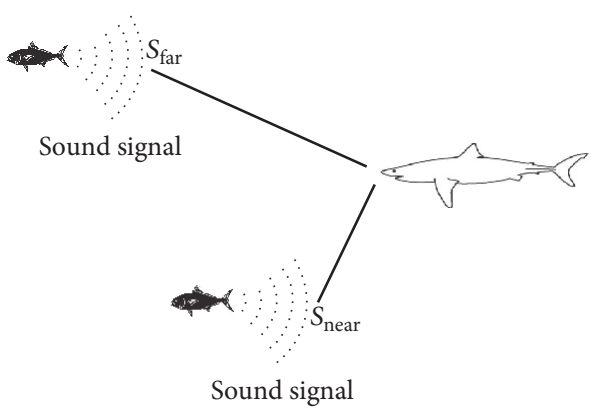

Figure 1: Random motion.

these sounds due to different noises, available between the shark and the prey. The movement of the shark depends on the sounds of nearby $\left(S_{\text {near }}\right)$ or faraway $\left(S_{\text {far }}\right)$ prey. The motion of a shark is random until the probability of finding prey is less than or equal to the threshold value $\left(T_{p}\right)$. If the probability goes more than $T_{p}$, the shark starts moving in a shrinking spiral motion to grab the prey.

3.2. Mathematical Model. In the initial phase, the shark searches for potential prey in a random motion. If the probability of getting the prey is high, then it circulates in a shrinking spiral motion to grab the prey.

3.2.1. Probability. The shark is a hungry animal; it searches for prey until potential prey is not located. The probability of finding prey tp is an increasing real number and it ranges from 0 to 1 . The threshold value of probability to find prey is $\mathbf{T}_{\mathbf{p}}$. If the shark estimates the probability to be more than the threshold value, it starts moving in a shrinking spiral motion to grab the prey.

3.2.2. Random Motion. The minimum and maximum audible sounds from nearby (faraway) prey are $S_{\text {near }}^{\min }$ and $S_{\text {near }}^{\max }\left(S_{\mathrm{far}}^{\min }\right.$ and $\left.S_{\mathrm{far}}^{\max }\right)$, respectively. A function rand( $(\cdot)$ returns a random value in the range $[0,1]$. Figure 1 shows the random motion of a shark.

The sound of nearby prey for iteration iter is formulated as

$$
S_{\text {near }}(\text { iter })=S_{\text {near }}^{\text {min }}+\operatorname{rand}(\cdot)\left(S_{\text {near }}^{\text {max }}-S_{\text {near }}^{\min }\right) .
$$

The sound of faraway prey for iteration iter is formulated as

$$
\left.S_{\text {far }} \text { (iter }\right)=S_{\text {far }}^{\min }+\operatorname{rand}(\cdot)\left(S_{\text {far }}^{\max }-S_{\text {far }}^{\min }\right) .
$$

The speed that defines the amount of change applied to the shark is modeled as

$$
\begin{aligned}
S_{d}(\text { iter })= & S_{d}(\text { iter }-1) \\
& +\left(S_{\text {near }}^{\min }+\operatorname{rand}(\cdot)\left(S_{\text {near }}^{\max }-S_{\text {near }}^{\min }\right)\right) \\
& *(\text { Pbest }(\text { iter })-P(\text { iter }-1)) \\
& +\left(S_{\text {far }}^{\min }+\operatorname{rand}(\cdot)\left(S_{\text {far }}^{\max }-S_{\text {far }}^{\min }\right)\right) \\
& *(\text { Gbest }-P(\text { iter }-1)) .
\end{aligned}
$$


TABLE 1: Constraints.

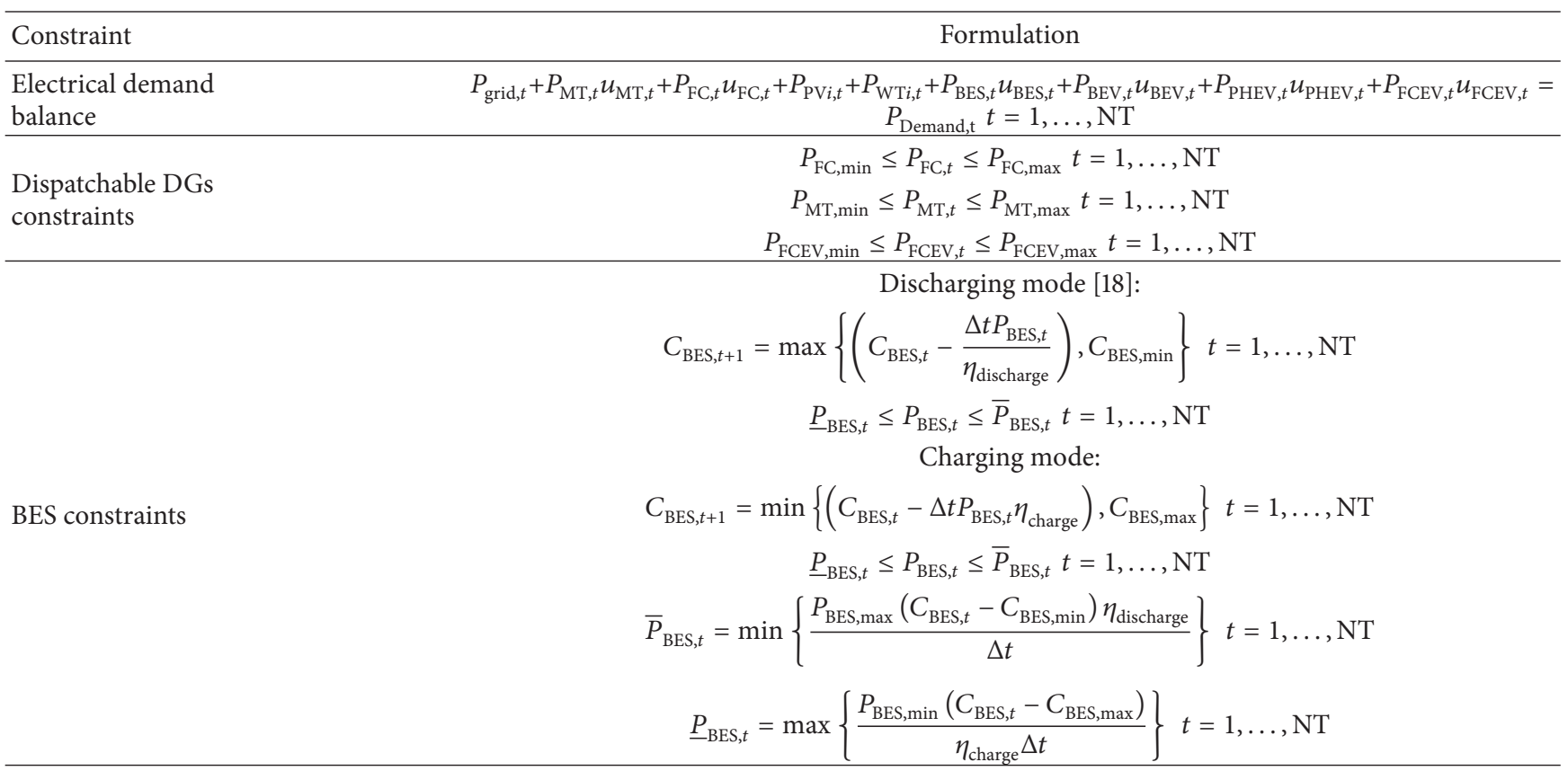

Discharging mode:

$$
C_{\mathrm{BEV}, t+1}=\max \left\{\left(C_{\mathrm{BEV}, t}-\frac{\Delta t P_{\mathrm{BEV}, t}}{\eta_{\text {discharge }}}\right), C_{\mathrm{BEV}, \min }\right\} t=1, \ldots, \mathrm{NT}
$$

$$
\underline{P}_{\mathrm{BES}, t} \leq P_{\mathrm{BES}, t} \leq \bar{P}_{\mathrm{BES}, t} t=1, \ldots, \mathrm{NT}
$$

Charging mode:

BEV constraints

$$
\begin{gathered}
C_{\mathrm{BEV}, t+1}=\min \left\{\left(C_{\mathrm{BEV}, t}-\Delta t P_{\mathrm{BEV}, t} \eta_{\text {charge }}\right), C_{\mathrm{BEV}, \max }\right\} t=1, \ldots, \mathrm{NT} \\
\underline{P}_{\mathrm{BEV}, t} \leq P_{\mathrm{BEV}, t} \leq \bar{P}_{\mathrm{BEV}, t} t=1, \ldots, \mathrm{NT} \\
\bar{P}_{\mathrm{BEV}, t}=\min \left\{\frac{P_{\mathrm{BEV}, \text { max }}\left(C_{\mathrm{BEV}, t}-C_{\mathrm{BEV}, \text { min }}\right) \eta_{\text {discharge }}}{\Delta t}\right\} t=1, \ldots, \mathrm{NT} \\
\underline{P}_{\mathrm{BEV}, t}=\max \left\{\frac{P_{\mathrm{BEV}, \text { min }}\left(C_{\mathrm{BEV}, t}-C_{\mathrm{BEV}, \max }\right)}{\eta_{\text {charge }} \Delta t}\right\} t=1, \ldots, \mathrm{NT}
\end{gathered}
$$

Discharging mode:

PHEV constraints

$$
\begin{gathered}
C_{\mathrm{PHEV}, t+1}=\max \left\{\left(C_{\mathrm{PHEV}, t}-\frac{\Delta t P_{\mathrm{PHEV}, t}}{\eta_{\text {discharge }}}\right), C_{\mathrm{PHEV}, \min }\right\} t=1, \ldots, \mathrm{NT} \\
\underline{P}_{\mathrm{PHEV}, t} \leq P_{\mathrm{PHEV}, t} \leq \bar{P}_{\mathrm{PHEV}, t} t=1, \ldots, \mathrm{NT} \\
\text { Charging mode: }
\end{gathered}
$$

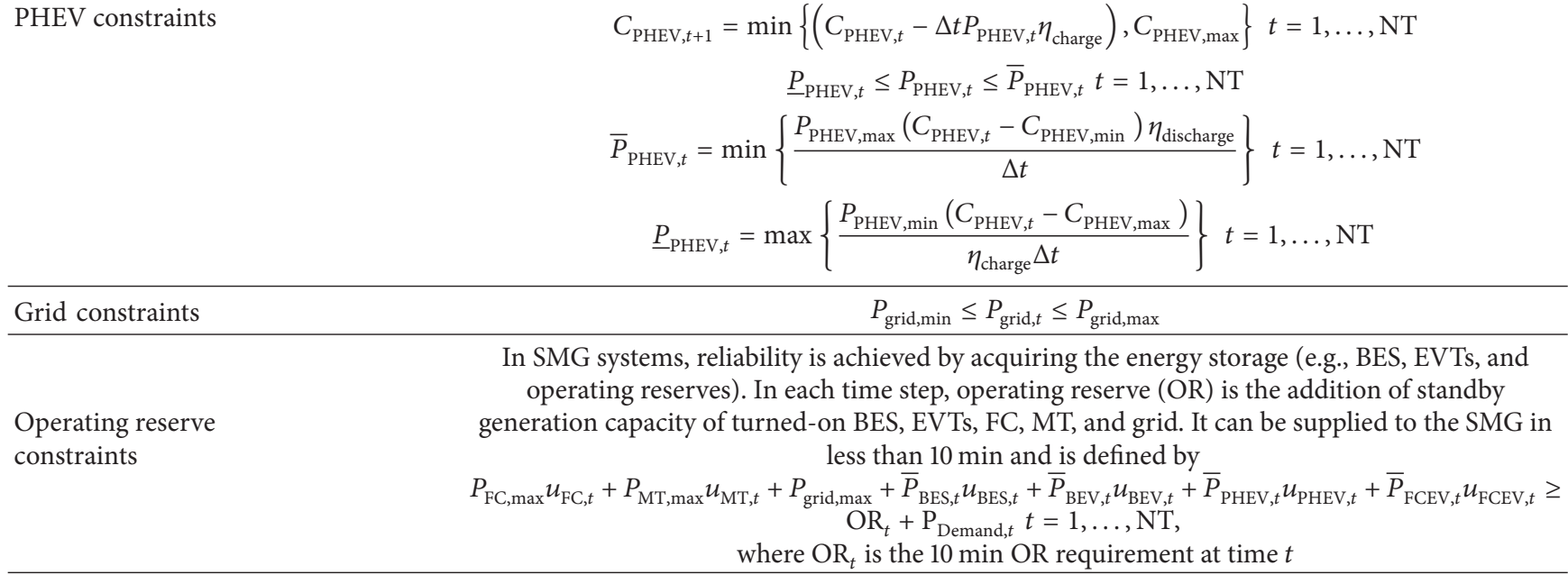




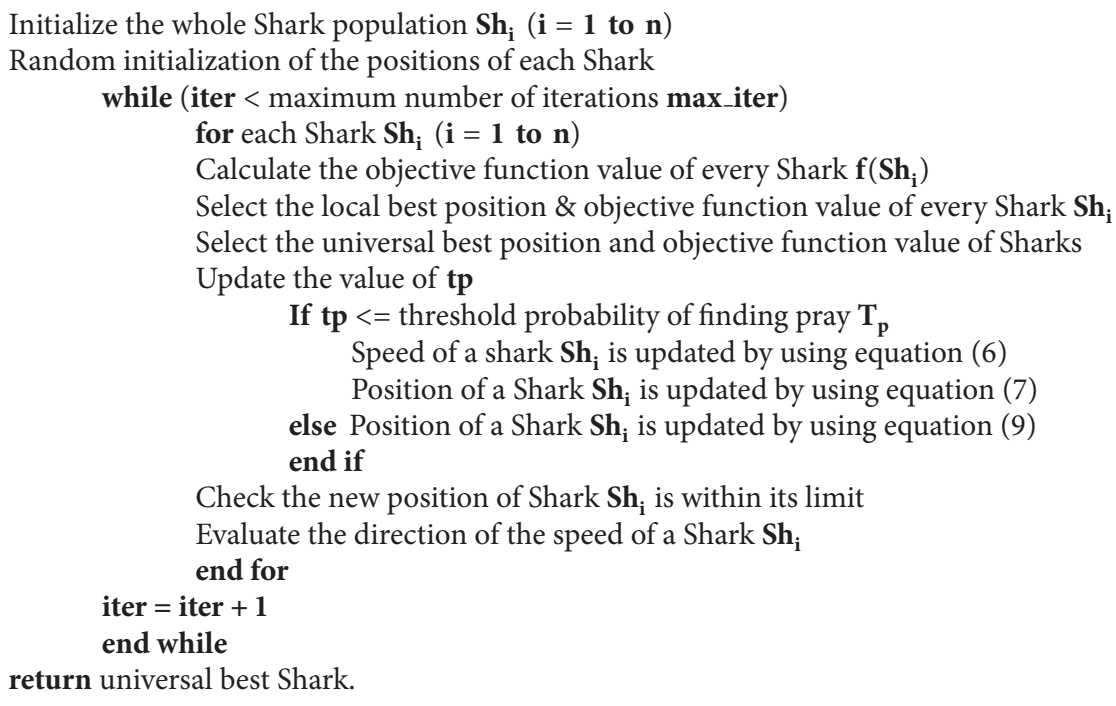

Algorithm 1

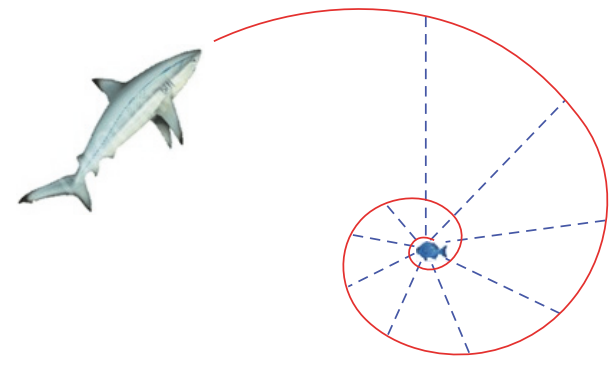

Figure 2: Spiral motion.

The position of a shark is evaluated as

$$
P(\text { iter })=P(\text { iter }-1)+S_{d}(\text { iter }) .
$$

3.2.3. Shrinking Spiral Motion. Let the position of the prey (the best solution achieved so far) be Gbest and the previous location (position) of the shark be $P($ iter -1$)$; then, the distance between them $D t$ is modeled as

$$
\text { Dt }(\text { iter })=\text { absolute }(\text { Gbest }-P(\text { iter }-1)) \text {. }
$$

Then, the position of a shark is evaluated as

$$
P(\text { iter })=D t(\text { iter }) * \cos (\theta(\text { iter })) * e^{x(\text { iter })}+\text { Gbest }
$$

where $x($ iter $)=a(1-(\operatorname{rand}(\cdot) *(2+$ iter $/$ max_iter $))), \theta($ iter $)=$ $2 \pi(x($ iter $) / a)$, and $\operatorname{rand}(\cdot)$ is a function that returns a random value in the range $[0,1]$. Figure 2 presents the spiral motion of the shark.

\subsection{Pseudocode of the Artificial Shark Optimization Algo-} rithm. See Algorithm 1.
3.4. Performance Assessment. To observe the efficiency of the proposed ASO technique, fifteen renowned unimodal, multimodal, and composite test functions are utilized. The parametric values of $S_{\text {near }}^{\max }\left(S_{\mathrm{far}}^{\max }\right)$ and $S_{\text {near }}^{\min }\left(S_{\mathrm{far}}^{\min }\right)$ are assumed to be 2 and 0 for this study, respectively. The formulation of these test functions is described in Tables 2(a), 2(b), and 2(c) [22].

Initially, three benchmark functions (1 unimodal and 2 multimodal) are selected to observe the change in performance with respect to the increase in population. The abovementioned test functions are applied on the ASO technique along with SA, GA, and PSO; 30 independent trials are made to observe the results. SA, GA, and PSO depend on the population number and the maximum number of function evaluations; therefore, they are best suited to compare the performance of ASO. Every standard function is evaluated for 50, 100, 250, and 500 dimensions. Four criteria, that is, mean, best, worst, and std. values, are selected to estimate the efficiency of optimization techniques [22]. The size of the population and the number of iterations for all the applied algorithms are 50 and 500, respectively. Table 3 presents the above-mentioned criteria for different dimensions of all benchmark functions obtained by ASO and other techniques. From the results, it is observed that, for the dimensions 100, 250 , and 500 , the proposed ASO technique calculates the best values for all four criteria. In case of 50 dimensions, the proposed algorithm ASO stands second.

Figure 3 shows the variation in fitness value with respect to the population for SA, GA, PSO, and ASO. From Figure 3, it is clear that the developed ASO algorithm shows less volatility as compared to other methods.

Five agents are deputed over 250 iterations to compute all standard functions and computed values are shown in Figure 4. The first row in Figure 4 shows the 2D representation of the functions. In the second row, the exploration and exploitation space of the best shark's position during 
TABLE 2

(a) Unimodal benchmark functions

\begin{tabular}{lccc}
\hline Functions & Dim & Range & $f$ min \\
\hline$F_{1}(x)=\sum_{i=1}^{n} x_{1}^{2}$ & 30,200 & {$[-100,100]$} & 0 \\
$F_{2}(x)=\sum_{i=1}^{n}\left|x_{i}\right|+\prod_{i=1}^{n} x_{i}$ & 30,200 & {$[-10,10]$} & 0 \\
$F_{3}(x)=\sum_{i=1}^{n}\left(\left[x_{i}+0.5\right]\right)^{2}$ & 30,200 & {$[-100,100]$} & 0 \\
$F_{4}(x)=\sum_{i=1}^{n} i x_{1}^{4}+\operatorname{random}[0,1)$ & 30,200 & {$[-1.28,1.28]$} & 0 \\
\hline
\end{tabular}

(b) Multimodal benchmark functions

\begin{tabular}{|c|c|c|c|}
\hline Functions & Dim & Range & $f \min$ \\
\hline$F_{5}(x)=\sum_{i=1}^{n}-x_{i} \sin \left(\sqrt{x_{i}}\right)$ & 30,200 & {$[-500,500]$} & $\begin{array}{l}-418.9829 * \\
\operatorname{Dim}^{\mathrm{a}}\end{array}$ \\
\hline$F_{6}(x)=-20 \exp \left(-0.2 \sqrt{\frac{1}{n} \sum_{i=1}^{n} x_{i}^{2}}\right)-\exp \left(\frac{1}{n} \sum_{i=1}^{n} \cos \left(2 \pi x_{i}\right)\right)+20+e$ & 30,200 & {$[-32,32]$} & 0 \\
\hline$F_{7}(x)=\frac{1}{4000} \sum_{i=1}^{n} x_{i}^{2}-\prod_{i=1}^{n} \cos \left(\frac{x_{i}}{\sqrt{i}}\right)+1$ & 30,200 & {$[-600,600]$} & 0 \\
\hline $\begin{array}{l}F_{8}(x)= \\
\frac{\pi}{n}\left\{10 \sin \left(\pi y_{1}\right)+\sum_{i=1}^{n-1}\left(y_{i}-1\right)^{2}\left[1+10 \sin ^{2}\left(\pi y_{i+1}\right)\right]+\left(y_{n}-1\right)^{2}\right\}+\sum_{i=1}^{n} u\left(x_{i}, 10,100,4\right) \\
y_{i}=1+\frac{x_{i}+1}{4} \\
u\left(x_{i}, a, k, m\right)= \begin{cases}k\left(x_{i}-a\right)^{m} & x_{i}>a \\
0 & -a<x_{i}<a \\
k\left(-x_{i}-a\right)^{m} & x_{i}<-a\end{cases} \end{array}$ & 30,200 & {$[-50,50]$} & 0 \\
\hline $\begin{array}{l}F_{9}(x)= \\
0.1\left\{\sin ^{2}\left(3 \pi x_{1}\right)+\sum_{i=1}^{n}\left(x_{i}-1\right)^{2}\left[1+\sin ^{2}\left(3 \pi x_{i}+1\right)\right]+\left(x_{n}-1\right)^{2}\left[1+\sin ^{2}\left(2 \pi x_{n}\right)\right]\right\}+ \\
\sum_{i=1}^{n} u\left(x_{i}, 5,100,4\right)\end{array}$ & 30,200 & {$[-50,50]$} & 0 \\
\hline
\end{tabular}

(c) Composite benchmark functions

\begin{tabular}{lcc}
\hline Functions & Dim & Range \\
\hline$F_{10}(\mathrm{CF} 1):$ & 10 & $f$ min \\
$f_{1}, f_{2}, f_{3}, \ldots, f_{10}=$ Sphere Function & {$[-5,5]$} \\
{$\left[\sigma_{1}, \sigma_{2}, \sigma_{3}, \ldots, \sigma_{10}\right]=[1,1,1, \ldots, 1]$} & 0 \\
{$\left[\lambda_{1}, \lambda_{2}, \lambda_{3}, \ldots, \lambda_{10}\right]=\left[\frac{5}{100}, \frac{5}{100}, \frac{5}{100}, \ldots, \frac{5}{100}\right]$} & 10 & {$[-5,5]$} \\
\hline$F_{11}(\mathrm{CF} 2):$ & 0 \\
$f_{1}, f_{2}, f_{3}, \ldots, f_{10}=$ Griewank's Function & \\
{$\left[\sigma_{1}, \sigma_{2}, \sigma_{3}, \ldots, \sigma_{10}\right]=[1,1,1, \ldots, 1]$} & 10 \\
{$\left[\lambda_{1}, \lambda_{2}, \lambda_{3}, \ldots, \lambda_{10}\right]=\left[\frac{5}{100}, \frac{5}{100}, \frac{5}{100}, \ldots, \frac{5}{100}\right]$} & {$[-5,5]$} \\
\hline$F_{12}(\mathrm{CF} 3):$ & \\
$f_{1}, f_{2}, f_{3}, \ldots, f_{10}=$ Griewank's Function & \\
{$\left[\sigma_{1}, \sigma_{2}, \sigma_{3}, \ldots, \sigma_{10}\right]=[1,1,1, \ldots, 1]$} & \\
{$\left[\lambda_{1}, \lambda_{2}, \lambda_{3}, \ldots, \lambda_{10}\right]=[1,1,1, \ldots, 1]$} & 0
\end{tabular}


(c) Continued.

\begin{tabular}{|c|c|c|c|}
\hline Functions & Dim & Range & $f$ min \\
\hline $\begin{array}{l}F_{13}(\mathrm{CF} 4) \text { : } \\
f_{1}, f_{2}=\text { Ackley's Function } \\
f_{3}, f_{4}=\text { Rastrigin's Function } \\
f_{5}, f_{6}=\text { Weierstrass Function } \\
f_{7}, f_{8}=\text { Griewank's Function } \\
f_{9}, f_{10}=\text { Sphere Function } \\
{\left[\sigma_{1}, \sigma_{2}, \sigma_{3}, \ldots, \sigma_{10}\right]=[1,1,1, \ldots, 1]} \\
{\left[\lambda_{1}, \lambda_{2}, \lambda_{3}, \ldots, \lambda_{10}\right]=\left[\frac{5}{32}, \frac{5}{32}, 1,1, \frac{5}{0.5}, \frac{5}{0.5}, \frac{5}{100}, \frac{5}{100}, \frac{5}{100}, \frac{5}{100}\right]}\end{array}$ & 10 & {$[-5,5]$} & 0 \\
\hline $\begin{array}{l}F_{14}(\text { CF5): } \\
f_{1}, f_{2}=\text { Rastrigin's Function } \\
f_{3}, f_{4}=\text { Weierstrass Function } \\
f_{5}, f_{6}=\text { Griewank's Function } \\
f_{7}, f_{8}=\text { Ackley's Function } \\
f_{9}, f_{10}=\text { Sphere Function } \\
{\left[\sigma_{1}, \sigma_{2}, \sigma_{3}, \ldots, \sigma_{10}\right]=[1,1,1, \ldots, 1]} \\
{\left[\lambda_{1}, \lambda_{2}, \lambda_{3}, \ldots, \lambda_{10}\right]=\left[\frac{1}{5}, \frac{1}{5}, \frac{5}{0.5}, \frac{5}{0.5}, \frac{5}{100}, \frac{5}{100}, \frac{5}{32}, \frac{5}{32}, \frac{5}{100}, \frac{5}{100}\right]}\end{array}$ & 10 & {$[-5,5]$} & 0 \\
\hline $\begin{array}{l}F_{15}(\mathrm{CF} 6) \text { : } \\
f_{1}, f_{2}=\text { Rastrigin's Function } \\
f_{3}, f_{4}=\text { Weierstrass Function } \\
f_{5}, f_{6}=\text { Griewank's Function } \\
f_{7}, f_{8}=\text { Ackley's Function } \\
f_{9}, f_{10}=\text { Sphere Function } \\
{\left[\sigma_{1}, \sigma_{2}, \sigma_{3}, \ldots, \sigma_{10}\right]=[0.1,0.2,0.3,0.4,0.5,0.6,0.7,0.8,0.9,1]} \\
{\left[\lambda_{1}, \lambda_{2}, \lambda_{3}, \ldots, \lambda_{10}\right]=} \\
{\left[0.1 * \frac{1}{5}, 0.2 * \frac{1}{5}, 0.3 * \frac{5}{0.5}, 0.4 * \frac{5}{0.5}, 0.5 * \frac{5}{100}, 0.6 * \frac{5}{100}, 0.7 * \frac{5}{32}, 0.8 * \frac{5}{32}, 0.9 * \frac{5}{100}, 1 * \frac{5}{100}\right]}\end{array}$ & 10 & {$[-5,5]$} & 0 \\
\hline
\end{tabular}

optimization is presented. The ASO method is inclined to investigate the potential areas of the search space comprehensively on the standard functions. This shows that the shark's agents are able to investigate the search space efficiently. Directional search history is presented in the third row in Figure 4, which shows in which direction sharks search the space efficiently.

The trajectory of the first variable of the first shark over 250 iterations is illustrated in the fourth row of Figure 4. There are rapid changes in the early iterations which decrease progressively over the course of iterations. As per Van den Bergh and Engelbrecht [23], this conduct ensures that a technique in due course converges to a point and investigates locally the search space. The average (mean) value of all sharks and convergence curves are presented in the last two rows of Figure 4, respectively. The mean value of sharks has a descending tendency on all of the standard functions. The same tendency is analyzed in convergence curves. This proves that the approximate value of the best search agent becomes more precise with the increase in iterations. An additional reality observed is the accelerated style of convergence curves as a consequence of the emphasis on exploration and exploitation. Tables 4(a), 4(b), and 4(c) present the comparison of the results obtained by the developed ASO algorithm with five different techniques (GA, PSO, states of matter search (SMS), bat algorithm (BA), and firefly (FF)) on fifteen standard benchmark functions under three different categories: unimodal, multimodal, and composite. It is observed from Table 4(a) that, in unimodal benchmark function $F 3$, the performance of ASO is the best, while in $F 1$ and $F 2$ it stands second and in F4 third. It is clear from Table 4(b) that, in multimodal benchmark functions $F 5, F 7$, and $F 8$, the performance of ASO is the best, while in $F 9$ it stands second and in $F 6$ third.

The best performance of the proposed algorithm ASO can be observed from Table 4(c) on complex composite benchmark functions, which are the reflection of the complex practical problems. Hence, it can be concluded that the developed ASO algorithm is best suited for the complex constrained practical problems. 
TABLE 3: Comparison of the results obtained by different algorithms.

\begin{tabular}{|c|c|c|c|c|c|c|}
\hline Function & $D$ & Criteria & SA & GA & PSO & ASO \\
\hline \multirow{16}{*}{ Sphere } & \multirow{4}{*}{50} & Mean & $2.80 E+00$ & $1.08 E+00$ & $3.69 E-01$ & $3.25 E-02$ \\
\hline & & Best & $5.90 E-03$ & $3.77 E-01$ & $8.66 E-02$ & $6.69 E-03$ \\
\hline & & Worst & $1.07 E+01$ & $2.31 E+00$ & $5.70 E-01$ & $7.00 E-02$ \\
\hline & & Std. & $3.99 E+00$ & $6.54 E-01$ & $2.02 E-01$ & $2.38 E-02$ \\
\hline & \multirow{5}{*}{100} & Mean & $1.96 E+02$ & $1.37 E+01$ & $6.12 E+00$ & $5.25 E-01$ \\
\hline & & Best & $1.57 E+02$ & $6.77 E+00$ & $3.00 E+00$ & $6.59 E-02$ \\
\hline & & Worst & $2.43 E+02$ & $1.88 E+01$ & $1.07 E+01$ & $8.90 E-01$ \\
\hline & & Std. & $3.90 E+01$ & $4.56 E+00$ & $2.60 E+00$ & $2.64 E-01$ \\
\hline & & Mean & $8.48 E+02$ & $1.55 E+02$ & $8.17 E+01$ & $1.96 E+00$ \\
\hline & \multirow{3}{*}{250} & Best & $8.19 E+02$ & $1.38 E+02$ & $6.23 E+01$ & $3.41 E-01$ \\
\hline & & Worst & $8.67 E+02$ & $1.92 E+02$ & $1.43 E+02$ & $3.67 E+00$ \\
\hline & & Std. & $1.87 E+01$ & $1.93 E+01$ & $3.09 E+01$ & $1.29 E+00$ \\
\hline & \multirow{4}{*}{500} & Mean & $3.54 E+25$ & $6.07 E+02$ & $8.36 E+02$ & $1.46 E+01$ \\
\hline & & Best & $4.87 E+16$ & $5.46 E+02$ & $3.02 E+02$ & $1.02 E+00$ \\
\hline & & Worst & $1.77 E+26$ & $6.51 E+02$ & $9.93 E+02$ & $2.70 E+01$ \\
\hline & & Std. & $7.08 E+25$ & $3.76 E+01$ & $2.68 E+02$ & $9.66 E+00$ \\
\hline \multirow{16}{*}{ Rastrigin } & \multirow{4}{*}{50} & Mean & $9.29 E+01$ & $1.19 E+02$ & $9.37 E+01$ & $2.63 E-03$ \\
\hline & & Best & $8.56 E+01$ & $8.54 E+01$ & $7.26 E+01$ & $3.49 E-04$ \\
\hline & & Worst & $1.02 E+02$ & $1.42 E+02$ & $1.46 E+02$ & $7.37 E-03$ \\
\hline & & Std. & $5.72 E+00$ & $2.13 E+01$ & $2.67 E+01$ & $2.57 E-03$ \\
\hline & \multirow{5}{*}{100} & Mean & $2.78 E+02$ & $2.69 E+02$ & $2.03 E+02$ & $2.11 E+00$ \\
\hline & & Best & $2.72 E+02$ & $2.40 E+02$ & $1.65 E+02$ & $1.46 E+00$ \\
\hline & & Worst & $2.90 E+02$ & $2.99 E+02$ & $2.25 E+02$ & $2.89 E+00$ \\
\hline & & Std. & $7.18 E+00$ & $2.39 E+01$ & $2.26 E+01$ & $5.13 E-01$ \\
\hline & & Mean & $1.60 E+03$ & $1.25 E+03$ & $7.07 E+02$ & $1.45 E+00$ \\
\hline & \multirow{3}{*}{250} & Best & $1.53 E+03$ & $9.89 E+02$ & $6.07 E+02$ & $1.52 E-01$ \\
\hline & & Worst & $1.73 E+03$ & $1.52 E+03$ & $7.86 E+02$ & $3.57 E+00$ \\
\hline & & Std. & $7.21 E+01$ & $1.73 E+02$ & $6.18 E+01$ & $1.49 E+00$ \\
\hline & \multirow{4}{*}{500} & Mean & $4.76 E+03$ & $2.89 E+03$ & $2.16 E+03$ & $3.56 E+00$ \\
\hline & & Best & $4.53 E+03$ & $2.58 E+03$ & $2.04 E+03$ & $1.44 E+00$ \\
\hline & & Worst & $4.97 E+03$ & $3.04 E+03$ & $2.33 E+03$ & $9.72 E+00$ \\
\hline & & Std. & $1.55 E+02$ & $1.67 E+02$ & $1.25 E+02$ & $3.13 E+00$ \\
\hline \multirow{16}{*}{ Griewank } & \multirow{4}{*}{50} & Mean & $1.72 E-04$ & $1.54 E+00$ & $9.73 E-02$ & $2.85 E-03$ \\
\hline & & Best & $1.46 E-04$ & $1.32 E+00$ & $5.37 E-02$ & $3.69 E-04$ \\
\hline & & Worst & $1.99 E-04$ & $1.75 E+00$ & $1.58 E-01$ & $3.70 E-03$ \\
\hline & & Std. & $1.91 E-05$ & $1.51 E-01$ & $4.00 E-02$ & $1.26 E-03$ \\
\hline & \multirow{5}{*}{100} & Mean & $6.33 E+00$ & $1.84 E+01$ & $1.35 E+00$ & $1.00 E-01$ \\
\hline & & Best & $5.16 E+00$ & $1.38 E+01$ & $1.07 E+00$ & $3.81 E-03$ \\
\hline & & Worst & $7.07 E+00$ & $2.30 E+01$ & $1.76 E+00$ & $2.91 E-01$ \\
\hline & & Std. & $6.54 E-01$ & $2.91 E+00$ & $2.58 E-01$ & $1.10 E-01$ \\
\hline & & Mean & $1.07 E+03$ & $2.35 E+02$ & $3.02 E+01$ & $1.23 E+00$ \\
\hline & \multirow{3}{*}{250} & Best & $1.03 E+03$ & $2.03 E+02$ & $2.64 E+01$ & $7.11 E-01$ \\
\hline & & Worst & $1.15 E+03$ & $2.64 E+02$ & $3.90 E+01$ & $1.88 E+00$ \\
\hline & & Std. & $4.04 E+01$ & $2.00 E+01$ & $4.71 E+00$ & $3.92 E-01$ \\
\hline & \multirow{4}{*}{500} & Mean & $5.12 E+03$ & $1.12 E+03$ & $2.14 E+02$ & $7.52 E-01$ \\
\hline & & Best & $5.03 E+03$ & $1.02 E+03$ & $2.08 E+02$ & $1.29 E-03$ \\
\hline & & Worst & $5.21 E+03$ & $1.29 E+03$ & $2.28 E+02$ & $1.37 E+00$ \\
\hline & & Std. & $6.39 E+01$ & $1.02 E+02$ & $7.10 E+00$ & $5.49 E-01$ \\
\hline
\end{tabular}




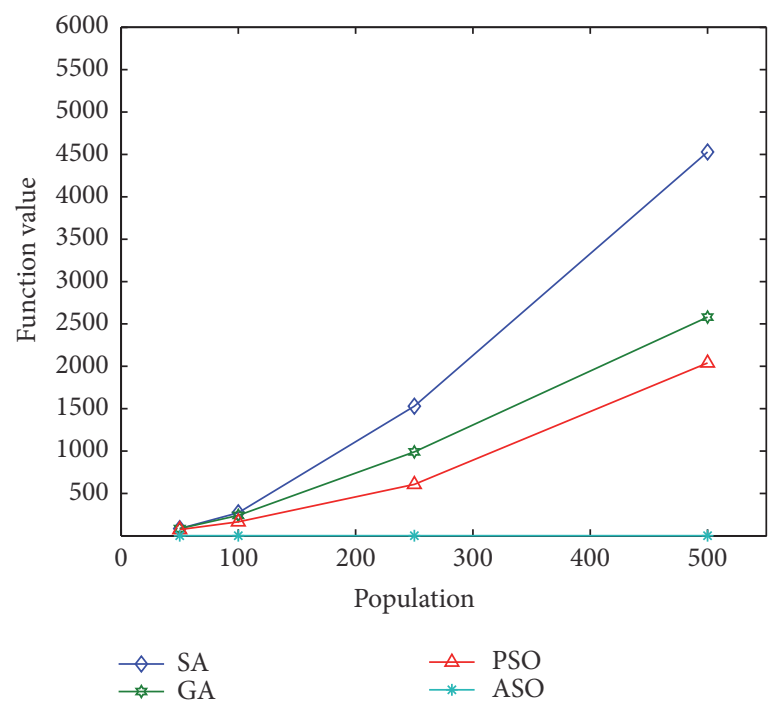

(a)

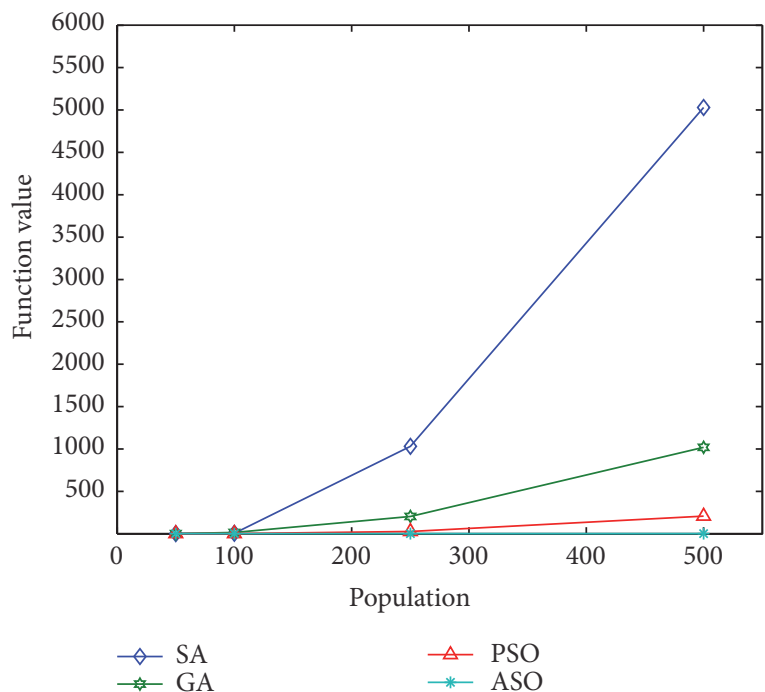

(c)

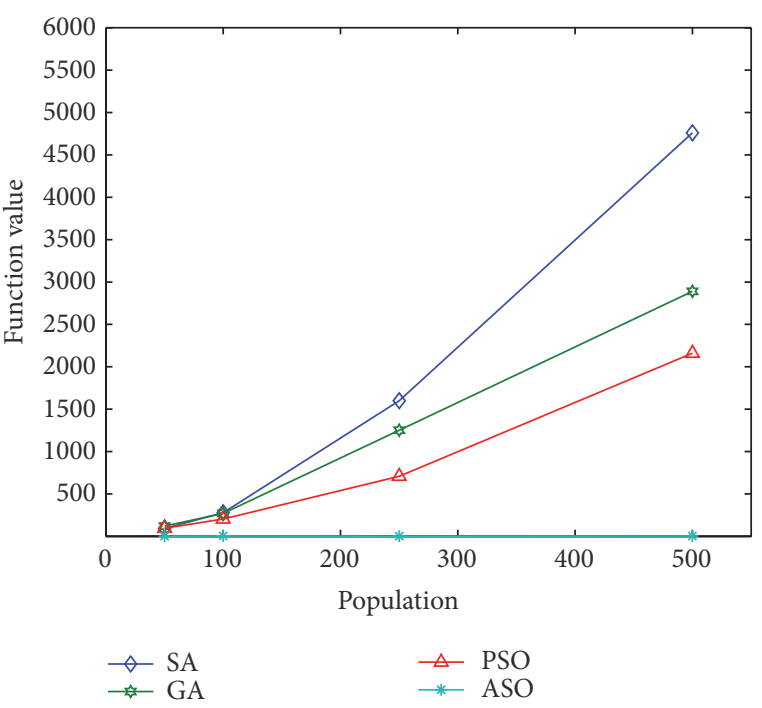

(b)

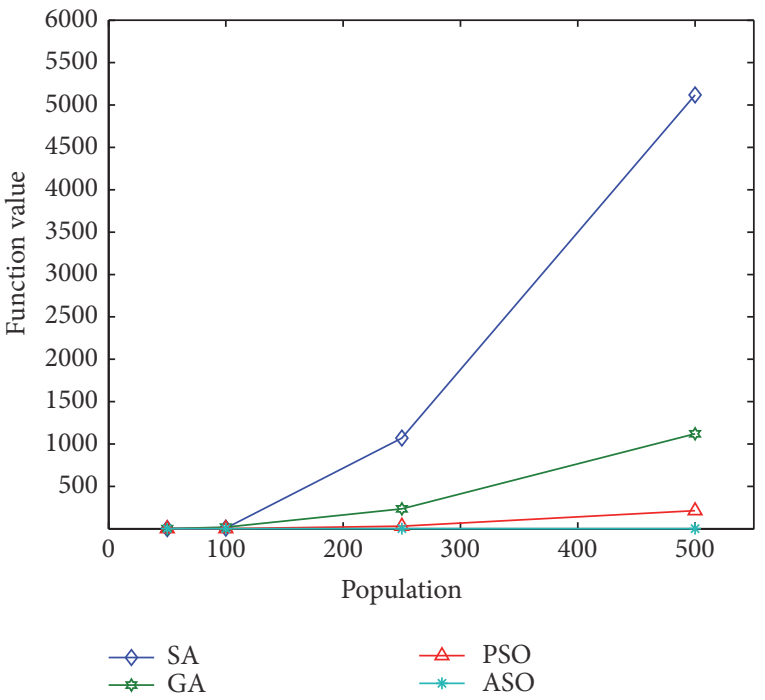

(d)

FIGURE 3: Fitness value variations with respect to population.

Figure 5 provides the comparison between different techniques on the basis of their convergence characteristics using different benchmark functions. Figure 5 demonstrates that the ASO illustrates the best convergence for composite and multimodal benchmark functions.

\section{Result and Discussion}

The proposed optimization model is utilized to solve the "economically controlled problem" of SMG. The legitimacy and efficacy of ASO are assessed and it is applied for the upgraded SMG system.
4.1. Description of a SMG Test System. To evaluate the legitimacy and efficacy of the proposed framework, ASO is applied on an advanced low voltage SMG system as shown in Figure 6. The SMG consists of various DGs such as PV, $\mathrm{WT}, \mathrm{MT}, \mathrm{FC}$, and Li-ion BES. In addition, the proposed SMG system consists of EVTs (BEV, PHEV, and FCEV) technology. In this work, the FCEV is considered as the DG source. Table 5 presents the coefficients and generation limits which are used in the projected approach. If the SMG under study has MT, FC, FCEV, PV, WT, BES, BEV, and PHEV, then the position of $m$ th search agent $X_{m}$ can be defined as 


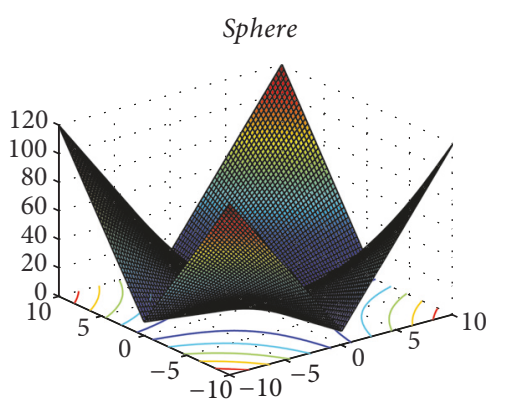

Standard functions

Rastrigin

Griewank
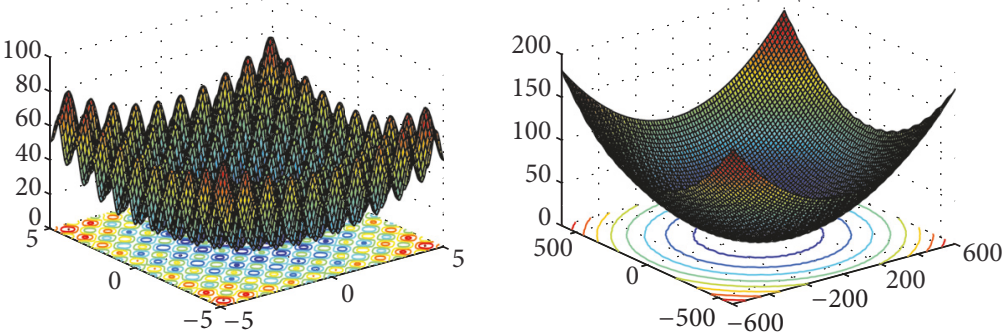

$2 \mathrm{D}$ representation
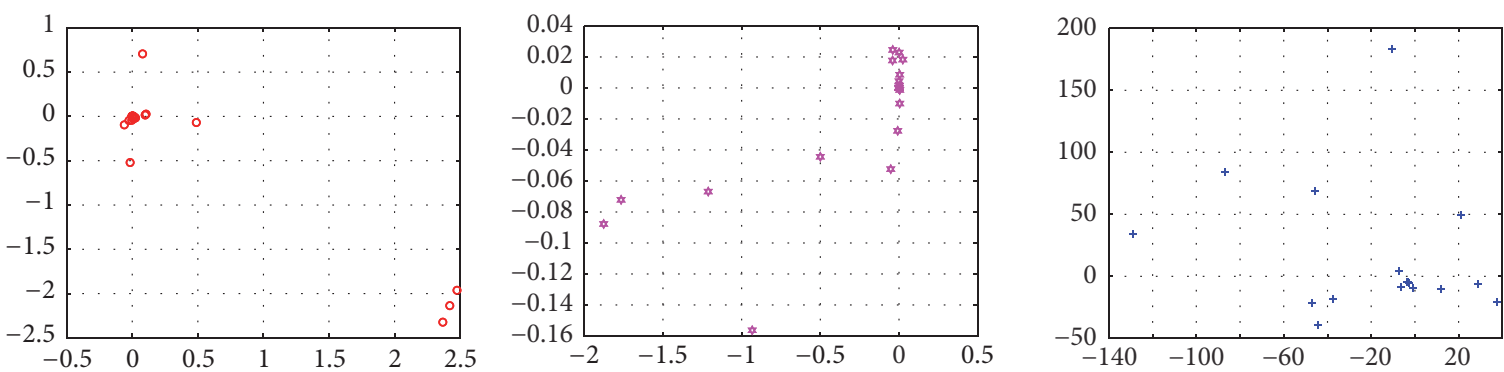

Search space
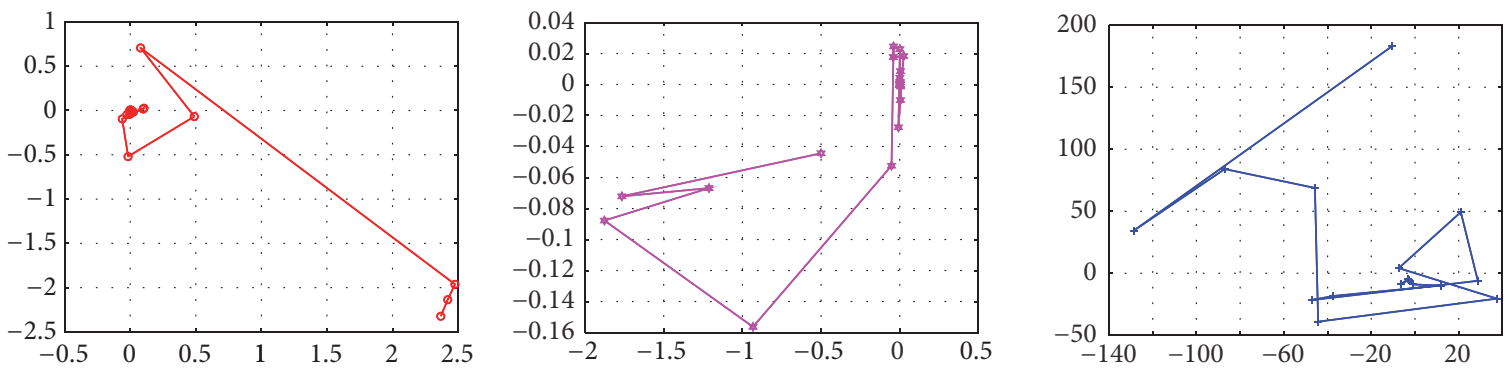

Directional search history
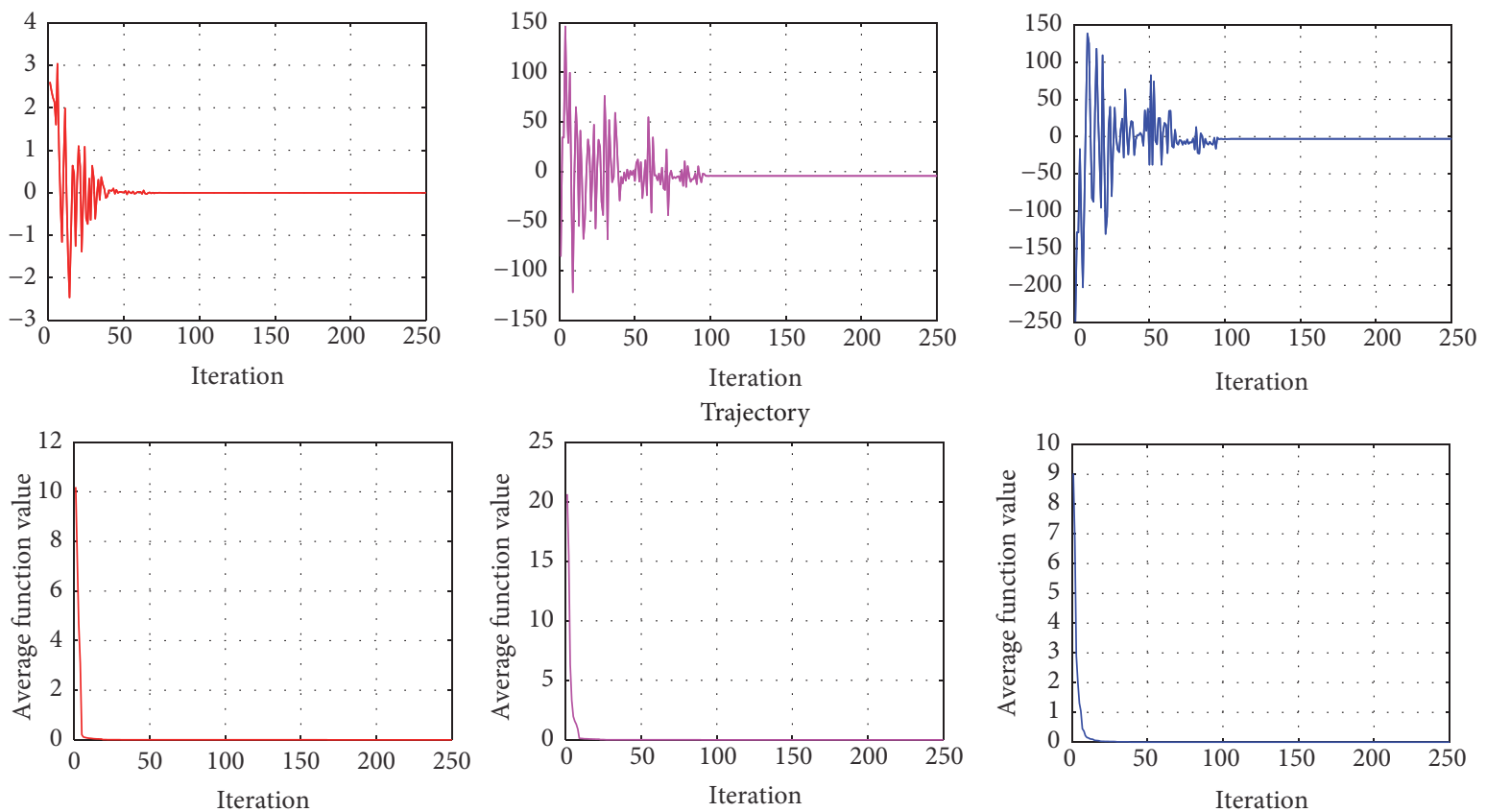

Average function value

FIgUre 4: Continued. 

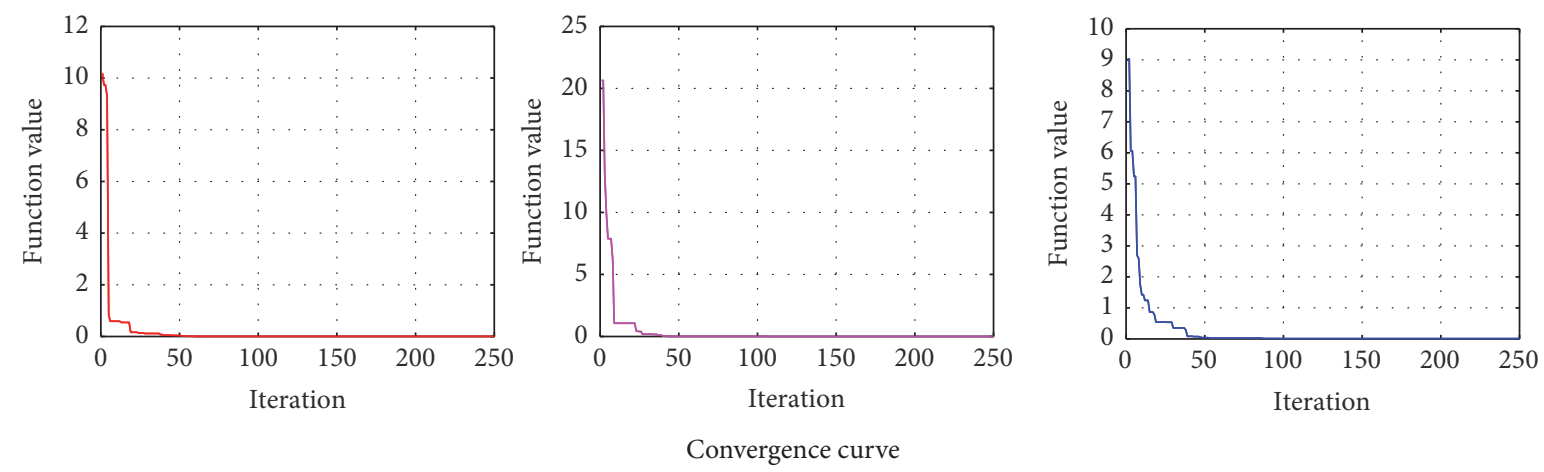

FIGURE 4: Search space, directional search history, trajectory in the first dimension, average function value of all sharks, and ASO convergence curve.

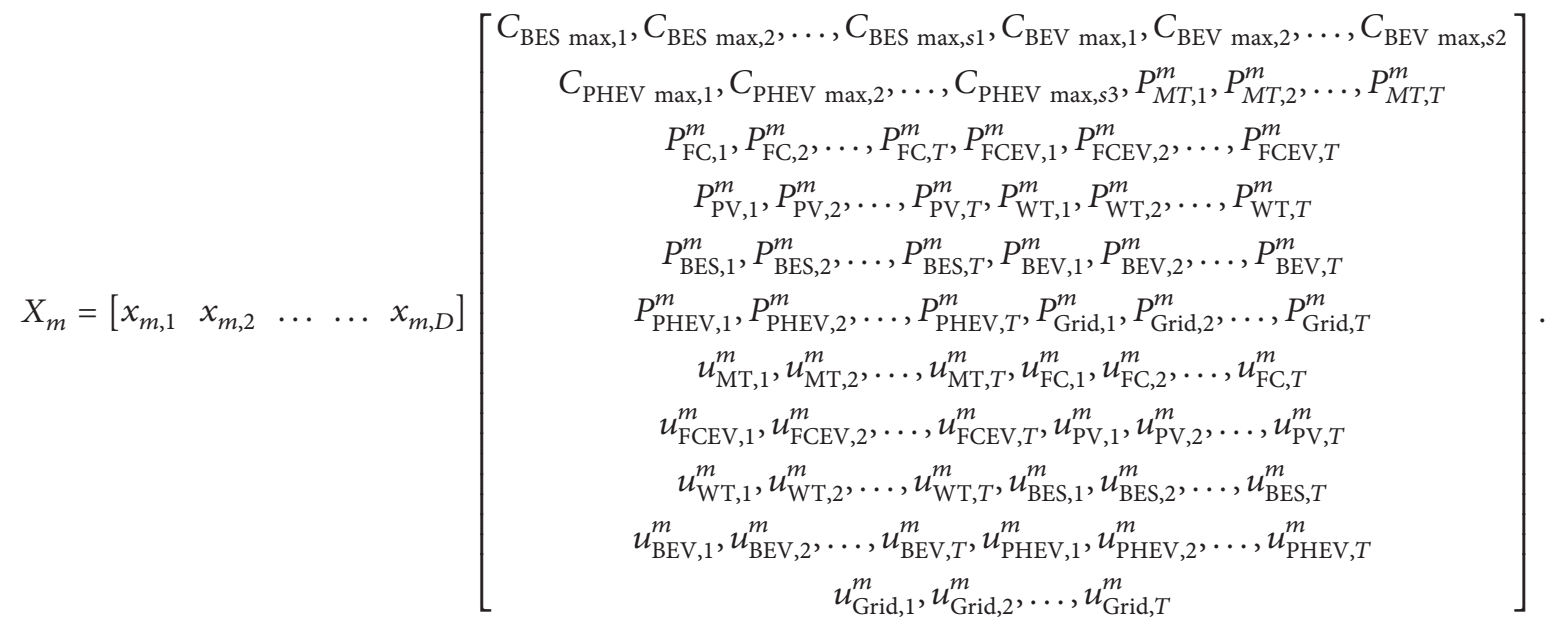

More information regarding the implementation of SMG can be found in $[18,24,25]$. It is supposed that all of the DGs generate active power at the unity power factor. In this system, it is assumed that $465(€ \mathrm{ct} / \mathrm{kW} \mathrm{h})$ and $15(€ \mathrm{ct} / \mathrm{kWh})$ are the fixed and maintenance cost of installation and operation of batteries [14]. The IR and LT for funding the installed batteries are 0.06 and 3, respectively. Ten-percent tax is adopted in this work. Batteries are charged and discharged as the same rate (i.e., 90\%). The MATLAB software on a PC with $2.4 \mathrm{GHz}$ Intel i5-4210U CPU and 4 GB RAM is used to implement different algorithms.

The algorithms are solved 30 times to validate the performance of ASO. The population size and the maximum number of iterations used in ASO are 50 and 250, respectively. For comparison, SA, GA, and PSO are used. For SA, 50, 0.99 , and 0.5 are considered as the population size, the temperature reduction rate, and mutation rate, respectively. For GA, 50, 0.7, and 0.1 are considered as population size, the crossover rate, and mutation rate, respectively. For PSO, 50, 1.5 , and 2 are considered as population size, local learning coefficients, and global learning coefficients, respectively. The inertia weight damping ratio is selected as 0.99 . The operation reserve and forecasted values of load demand are given in Figure 7.

In current work, two dissimilar scenarios are analyzed to describe the supremacy of the proposed framework.

Case 1. SMG with batteries (BES, BEV, and PHEV) in charging mode.

Case 2. SMG with batteries (BES, BEV, and PHEV) in discharging mode.

4.1.1. Case 1. For this scenario, the Li-ion batteries (an elementary component of the SMG) are appended in the form of BES, BEV, and PHEV in the SMG test system. The key advantage of the batteries in SMG is to sustain stability, make the RESs' integration possible, and improve the quality of power [26-28]. The Li-ion batteries start during the time period when there is no charge; therefore, the discharging is limited to the charging in earlier hours. To validate the effectiveness of selected batteries with optimum capacity, maximum sizes of batteries $\left(\mathrm{CBES}_{\max }, \mathrm{CBEV}_{\max }, \mathrm{CPHEV}_{\max }\right)$ are considered as the control parameter. The minimum and maximum capacity are set to 50 and $500 \mathrm{kWh}$, respectively. In [18], only 

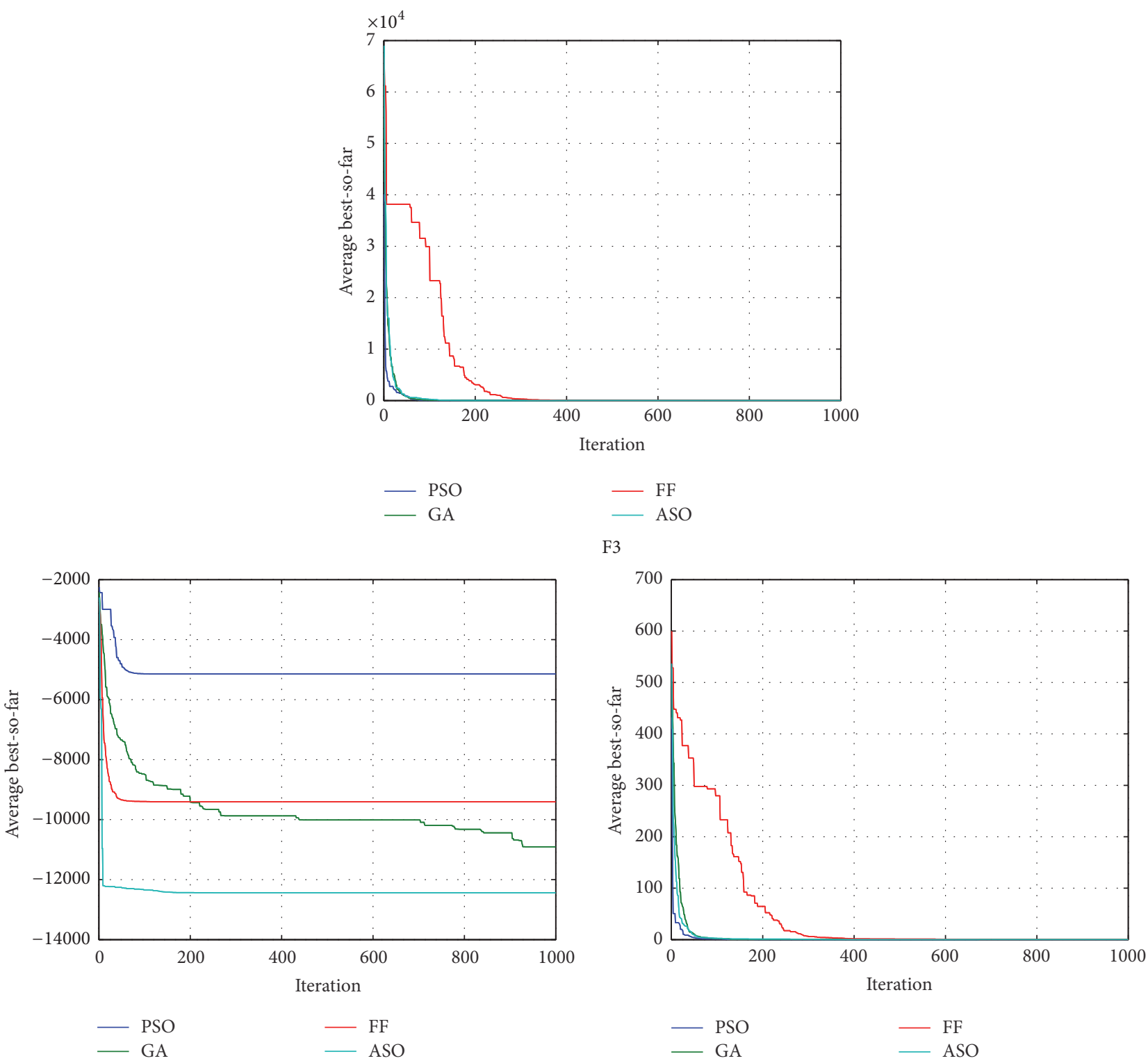

- FF

F5
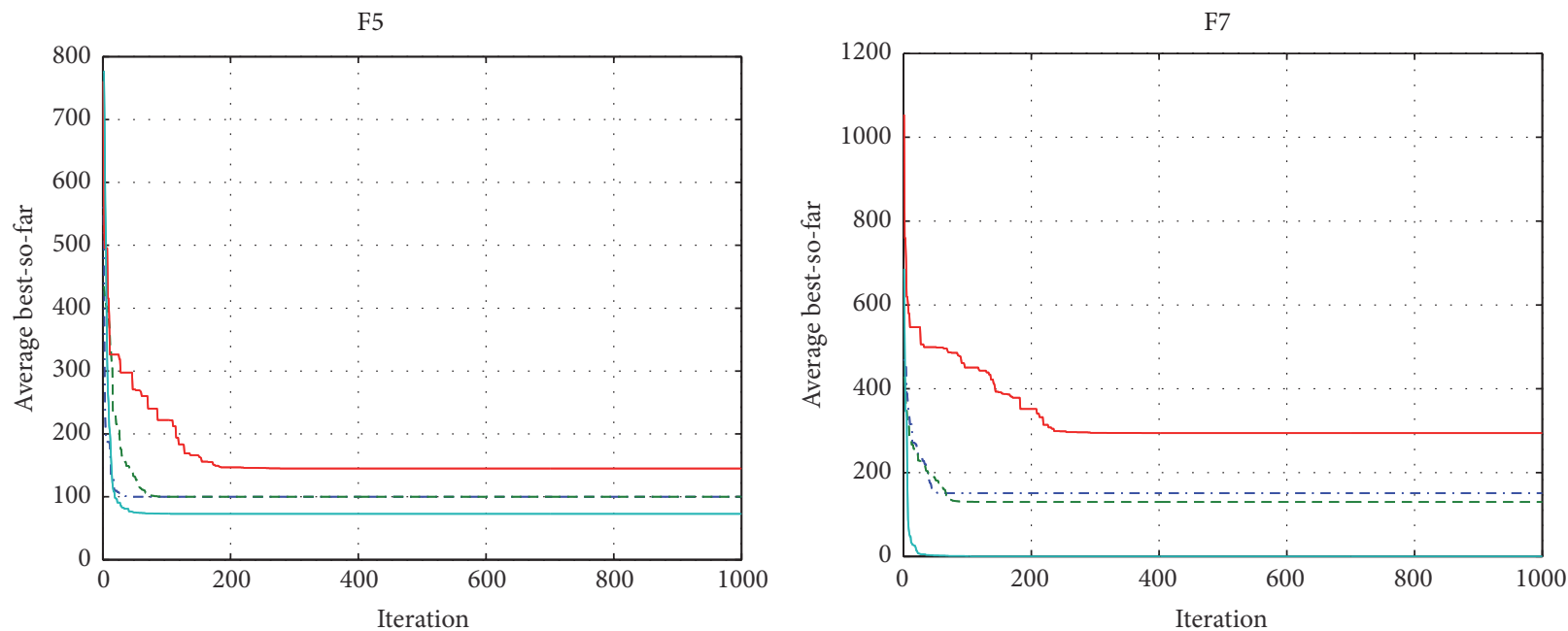

... PSO

— FF

... PSO

FF

- - GA

- ASO

$---\mathrm{GA}$

- ASO

FIGURE 5: Continued. 

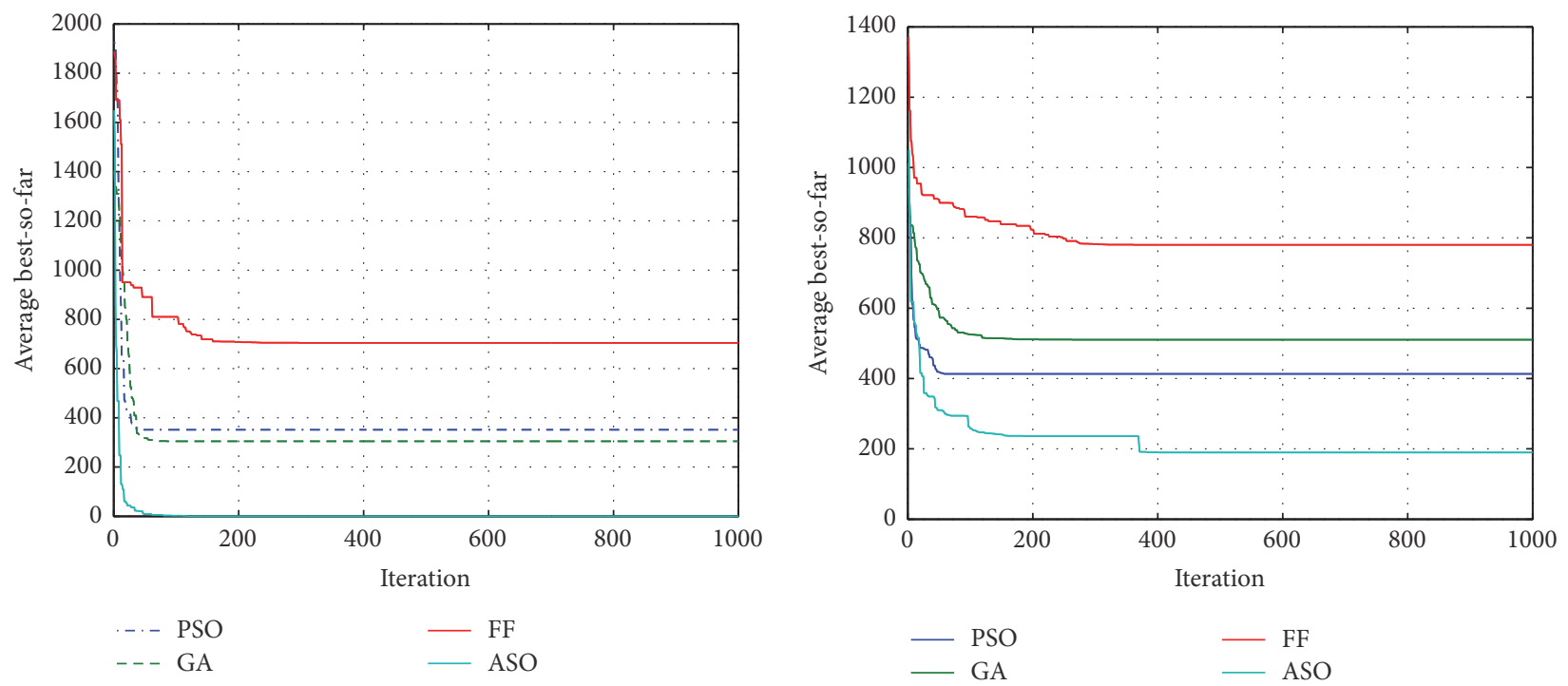

F12
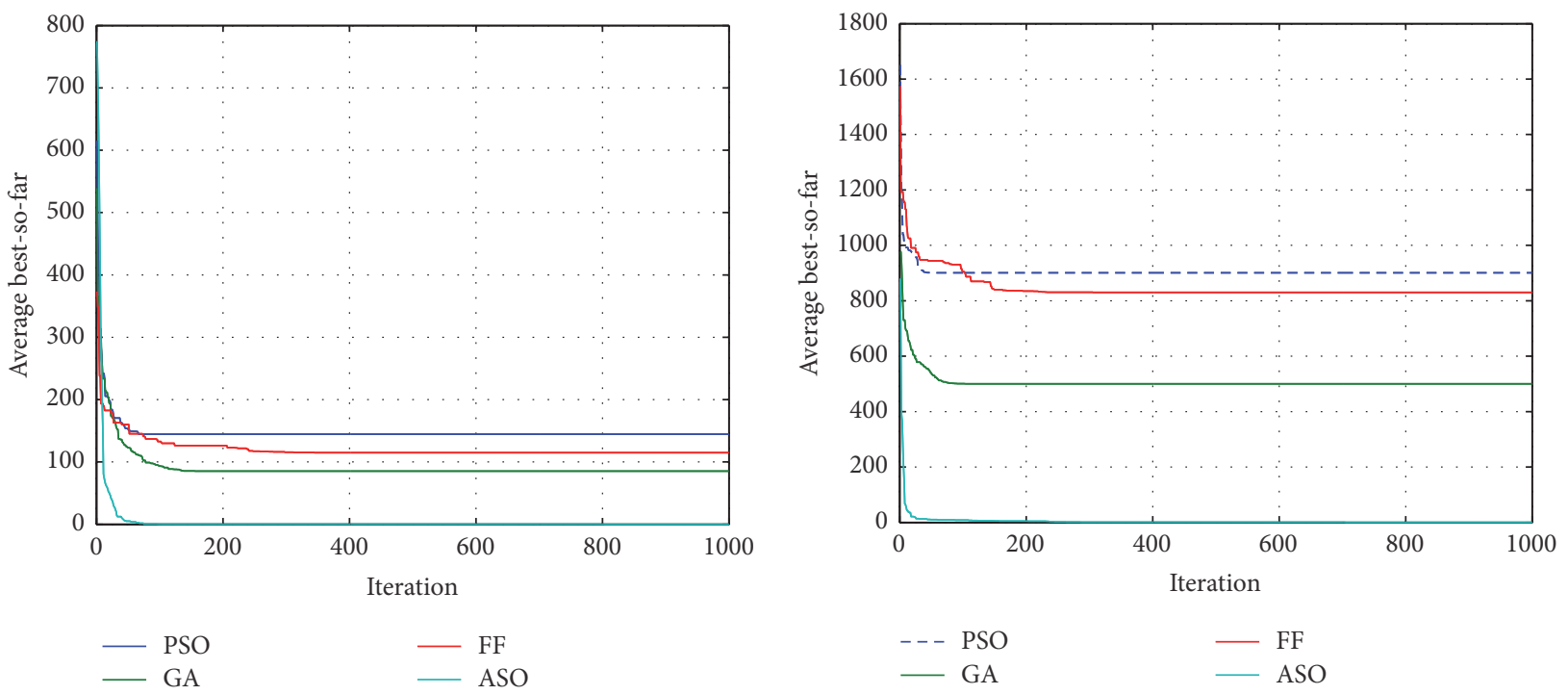

F14

F15

FIGURE 5: Comparison based on convergence characteristic.

$\mathrm{CBES}_{\max }$ is considered but not as a variable. However, in this work, $\mathrm{CBES}_{\max }, \mathrm{CBEV}_{\text {max }}$, and $\mathrm{CPHEV}_{\text {max }}$ are considered as control variables. From the above discussion, it is clear that the EOSMG has been solved for minimizing the total cost of operation. Additionally, the economical sizes of batteries as well as optimal output of MT, FC, PV, WT, FCEV, BEV, PHEV, BES, and grid are computed. Table 6 presents the optimal output of DGs, BES, EVTs, and utility calculated by ASO. The economical sizes of BES, BEV, and PHEV in this work are $50 \mathrm{kWh}$ each. The total operation cost of EOSMG in Case 2 is 1673.1215 (€ct/day). A comparison of the results obtained by different algorithms, depicted in Table 7, proves the superiority of ASO. The comparison between convergence curves of ASO, SA, GA, and PSO is given in Figure 8. It is evident from Figure 8 that the proposed method provides a better solution with a high convergence rate which is useful to solve the difficult optimization problems.

4.1.2. Case 2. For this scenario, all the batteries are fully charged; the power outputs of MT, FC, BES, BEV, PHEV, FCEV, PV, WT, and power grid in the SMG are shown in Table 8. Due to the economical power supplied by batteries, it is beneficial for EOSMG to purchase power from BES and EVTs. In this case, the system considers batteries of optimum size, $50 \mathrm{kWh}$, and the total operation costs will be 1882.362 (€ct/day). A comparison of the results computed by various techniques, depicted in Table 9, proves the superiority of ASO. For demonstrating efficiency of the ASO algorithm against SA, GA, and PSO, the convergence graph of these methods is shown in Figure 9. It is evident that the proposed 


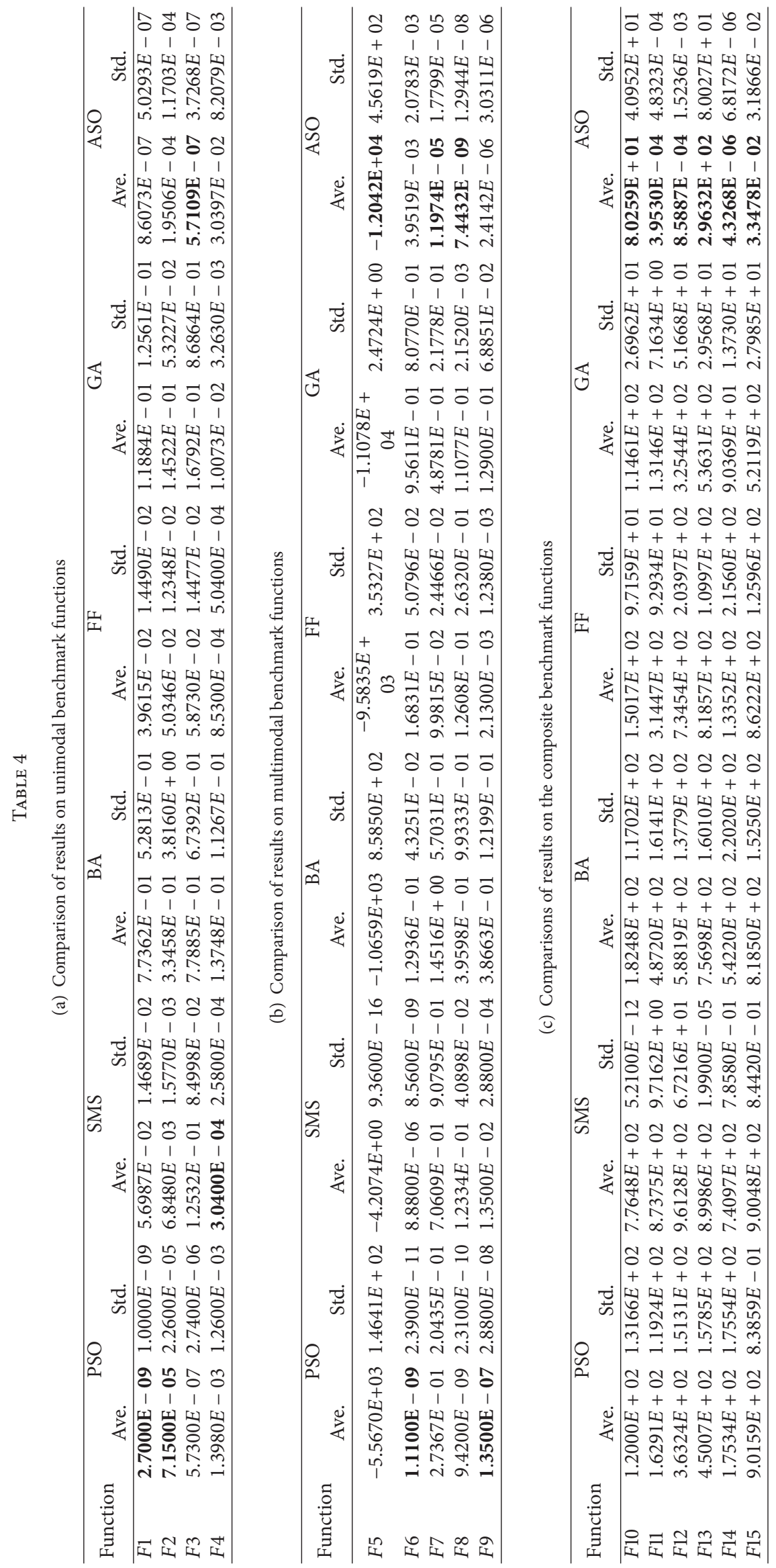




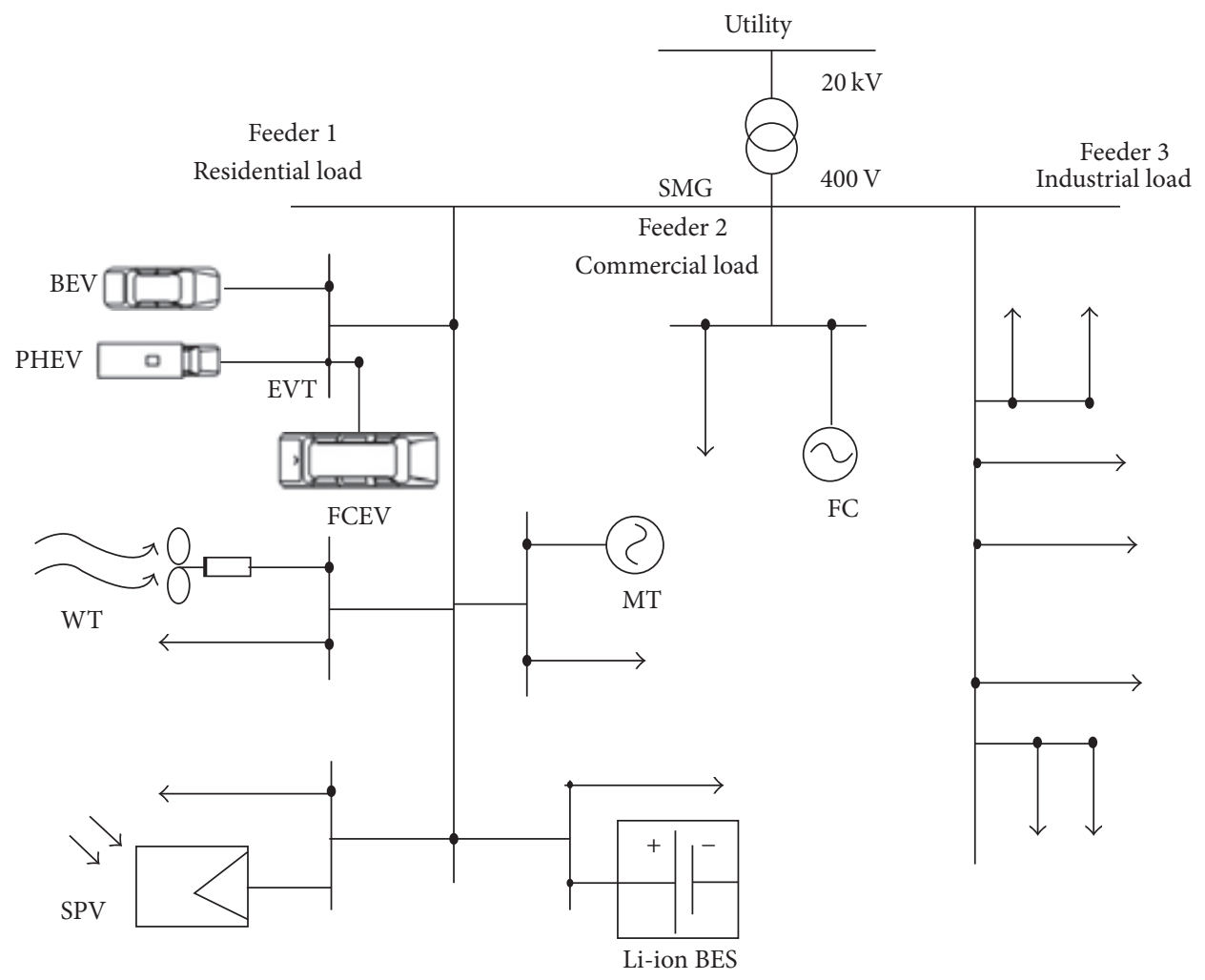

FIGURE 6: SMG test system.

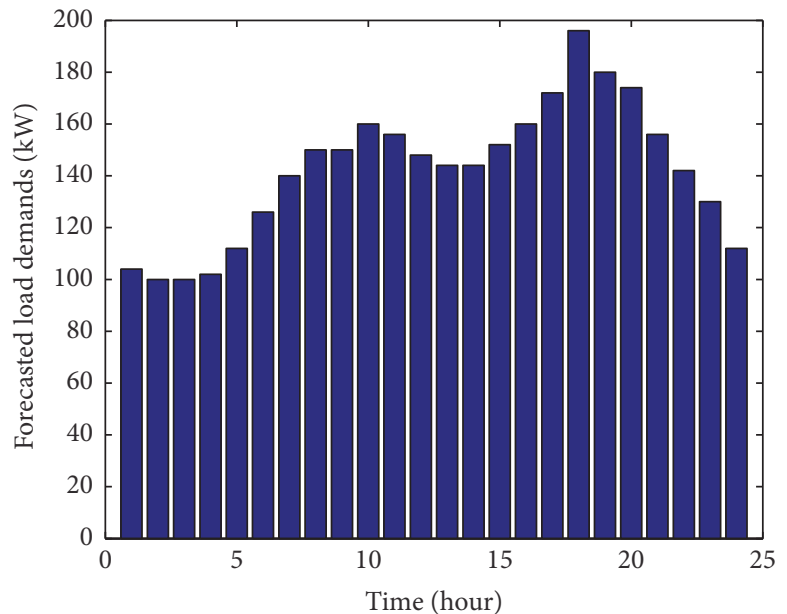

(a)

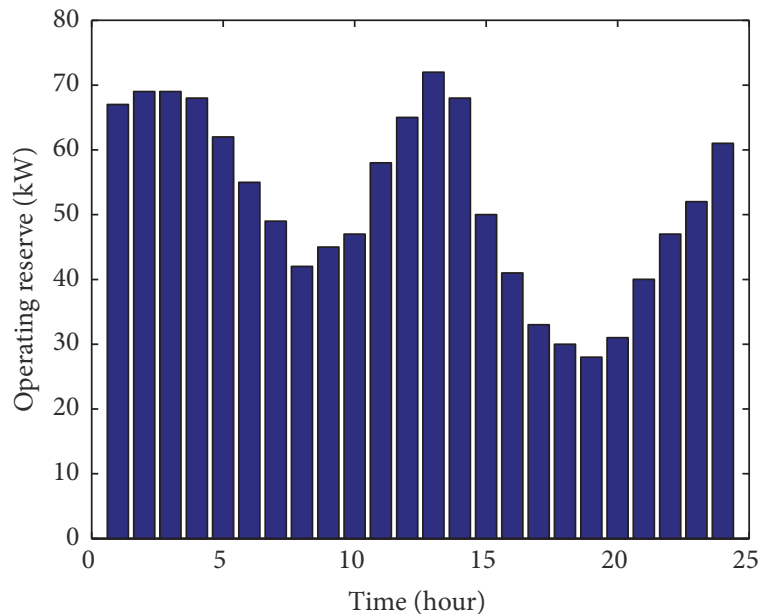

(b)

FIGURE 7: (a) Forecasted load demand and (b) operating reserve capacity.

method provides a better solution with a high convergence rate which is useful to solve difficult problems of optimization.

It can be concluded from the above discussion that the projected MG system, as an EOSMG, is widespread and sufficiently standard to be applied for an illustration of the inconsistency of RESs in the existence of optimal batteries sizing consideration.

The PV and WT output generated by our approach can be used as input to stochastic programming algorithms such as the point estimation technique or Monte Carlo simulation [29-31]. The proposed algorithm can be executed 


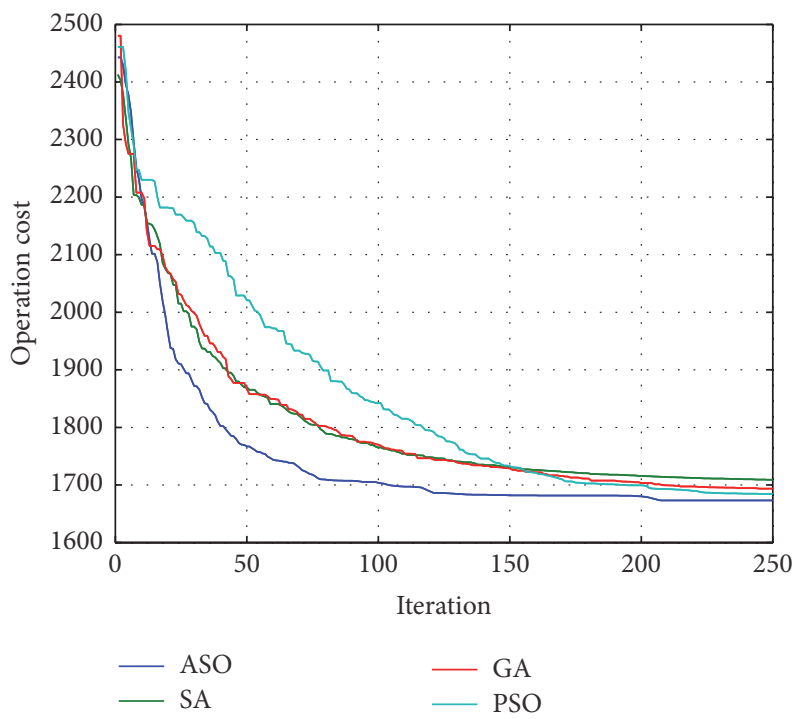

FIgURE 8: Convergence graph of ASO, SA, GA, and PSO for Case 1.

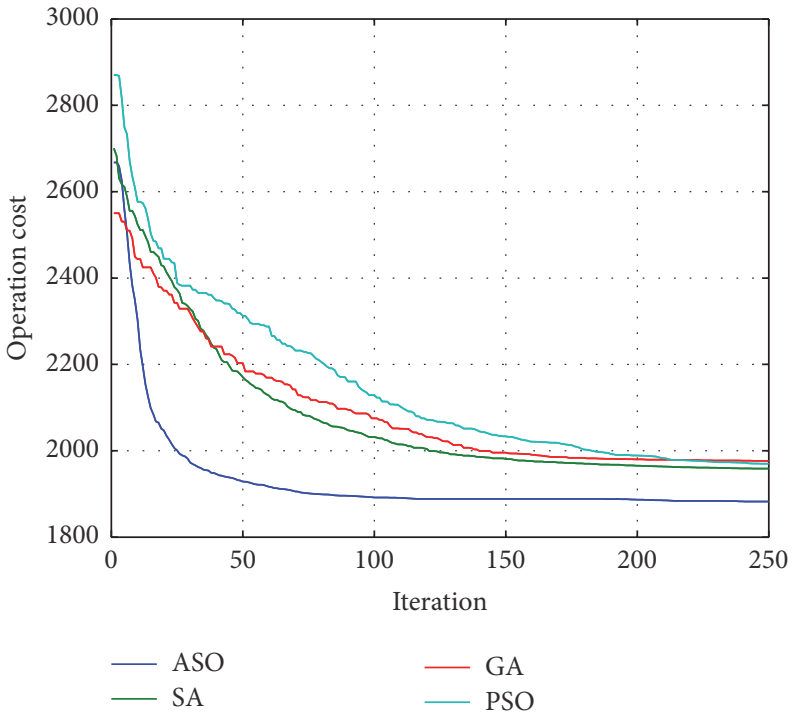

FIgURE 9: Convergence graph of ASO, SA, GA, and PSO for Case 2.

TABLE 5: The constraints limit and bids of the DGs, utility, BES, and EVTs.

\begin{tabular}{lccccc}
\hline Type & Min. power $(\mathrm{kW})$ & Max. power $(\mathrm{kW})$ & Bid $(€ c t / \mathrm{kWh})$ & OM $(€ c t / \mathrm{kWh})$ & 0.0446 \\
\hline MT & 6 & 30 & 0.457 & 0.08618 & Start-up $(€ c t)$ \\
FC & 3 & 30 & 0.294 & 0.08618 \\
FCEV & 3 & 30 & 0.294 & 0.2082 & 1.65 \\
PV & 0 & 25 & 2.584 & 0.5250 & - \\
WT & 0 & 15 & 1.073 & - & 0 \\
BES & -30 & 30 & 0.380 & - & 0 \\
BEV & -30 & 30 & 0.380 & - & 0 \\
PHEV & -30 & 30 & 0.380 & - \\
Grid & -30 & 30 & - & - \\
\hline
\end{tabular}




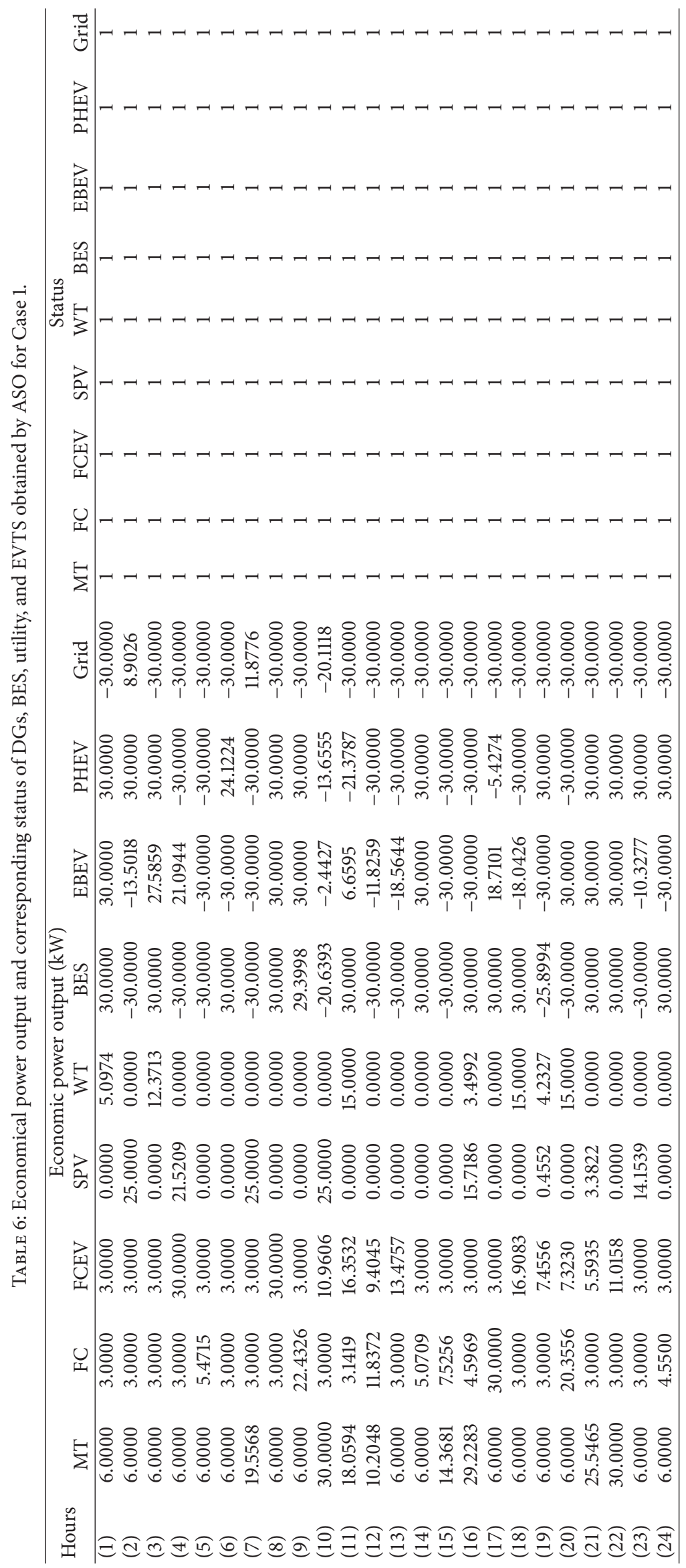


TABLE 7: Operation cost comparison for Case 1 (30 trials), €ct/day.

\begin{tabular}{|c|c|c|c|c|c|c|c|c|}
\hline Methodology & $\begin{array}{c}\text { Best } \\
\text { solution }\end{array}$ & $\begin{array}{c}\text { Worst } \\
\text { solution }\end{array}$ & $\begin{array}{l}\text { Average } \\
\text { solution }\end{array}$ & $\begin{array}{c}\text { Number of hits to } \\
\text { optimal solution }\end{array}$ & $\begin{array}{r}\text { Standard } \\
\text { deviation }\end{array}$ & $\begin{array}{c}\text { Number of } \\
\text { trials }\end{array}$ & $\begin{array}{c}\text { Population } \\
\text { size }\end{array}$ & Iterations \\
\hline ASO & 1673.1215 & 1764.3676 & 1690.75 & 26 & 15.603299 & 30 & 50 & 250 \\
\hline SA & 1709.0489 & 1799.2431 & 1760.19 & 20 & 23.13305 & 30 & 50 & 250 \\
\hline GA & 1693.493 & 1831.4027 & 1758.26 & 15 & 47.61386 & 30 & 50 & 250 \\
\hline PSO & 1684.3069 & 1843.4294 & 1717.13 & 11 & 52.96354 & 30 & 50 & 250 \\
\hline
\end{tabular}

with certain adjustments and achieve Pareto optimality [32]. The proposed method can also be used for incorporating EVTs for microgrid optimization.

The above-discussed features of the proposed framework can be stated as one of its significant benefits with respect to other methods.

The capacities of batteries affect both the fixed and the operational cost of SMG system. To verify the performance and illustrate the advantage of ASO over other methods, the minimum capacities of batteries are lowered to $5 \mathrm{kWh}$ and the experiments are conducted for 30 trials with 250 iterations and 50 search agents in Case 1 as well as Case 2. The results computed are stated in Tables 10 and 11.

It is clear from Tables 10 and 11 that the ASO algorithm computes consistently minimum batteries' capacities for Cases 1 and 2, whereas PSO, GA, and RCSA are computing batteries' capacities greater than the minimum capacity. As per the observation of Tables 10 and 11, it is concluded that ASO is capable of delivering optimal results with the least batteries' capacities; this is one of the advantages of the proposed ASO.

\section{Conclusion}

In this work, a new metaheuristic technique ASO is developed and applied as an effective method for solving the SMG economical optimization problem. An optimal model of SMG economical operation is developed with consideration of fuel, operation, and maintenance cost.

Numerous observations made are as follows.

The developed ASO algorithm shows less volatility as compared to other methods. The results obtained from unimodal and multimodal benchmark functions prove that the developed method stands either first or second with respect to GA, PSO, SMS, BA, FF, and SA in terms of convergence and average optimal value.

The best performance of the proposed algorithm ASO can be observed on complex composite benchmark functions, which represent the complex practical problems. Hence, it can be concluded that the developed ASO algorithm is best suited for the complex constrained practical problems.

The results obtained from the two case studies show that BES and EVTs can be incorporated within the SMG to decrease the cost. ASO algorithm computes consistently minimum batteries' capacities for Cases 1 and 2, whereas PSO, GA, and RCSA are computing batteries' capacities greater than the minimum capacity. The reduction in the overall cost is because BES and EVTs are used to store the additional power of RESs and return it appropriately as feedback whenever needed. Also, BES and EVTs make the RESs operation more stable.

The advantages of EVT are its mobility and ability to supply the stored power to the energy deficient areas during peak hours. The benefit of batteries is to handle the instability and intermittency of RESs. Therefore, the latest EVTs (BEV, PHEV, and FCEV) along with BES are used to store excess power during high availability in SMG.

One of the open problems is to propose a new metaheuristic algorithm which can provide results better than those obtained in this work. The next futuristic enhancement may be to use other latest storage devices to improve the performance of SMG.

\section{Notations}

\section{Abbreviations}

BES: Battery energy storage

BEV: Battery electric vehicle

PHEV: Plug-in battery electric vehicle

DG: Distributed generator

FX: $\quad$ Fixed cost

FCTs: Fuel cell technologies

FCEV: Fuel cell electric vehicle

FCPG: Fuel cell power generator

GA: Genetic algorithm

IR: Interest rate

LT: $\quad$ Lifetime

MC: Maintenance cost

MG: Microgrid

MGCO: Microgrid central operator

MT: Microturbine

OR: Operating reserve

PSO: Particle swarm optimization

IBA: Improved bat algorithm

SPV: Solar photovoltaic

RES: Renewable energy source

SMG: Smart microgrid

EVTs: Electric vehicle technologies

V2G: Vehicle to grid

$\mathrm{V} 2 \mathrm{H}$ : Vehicle to home

G2V: Grid to vehicle

ASO: Artificial shark optimization

PC: Personal computer 


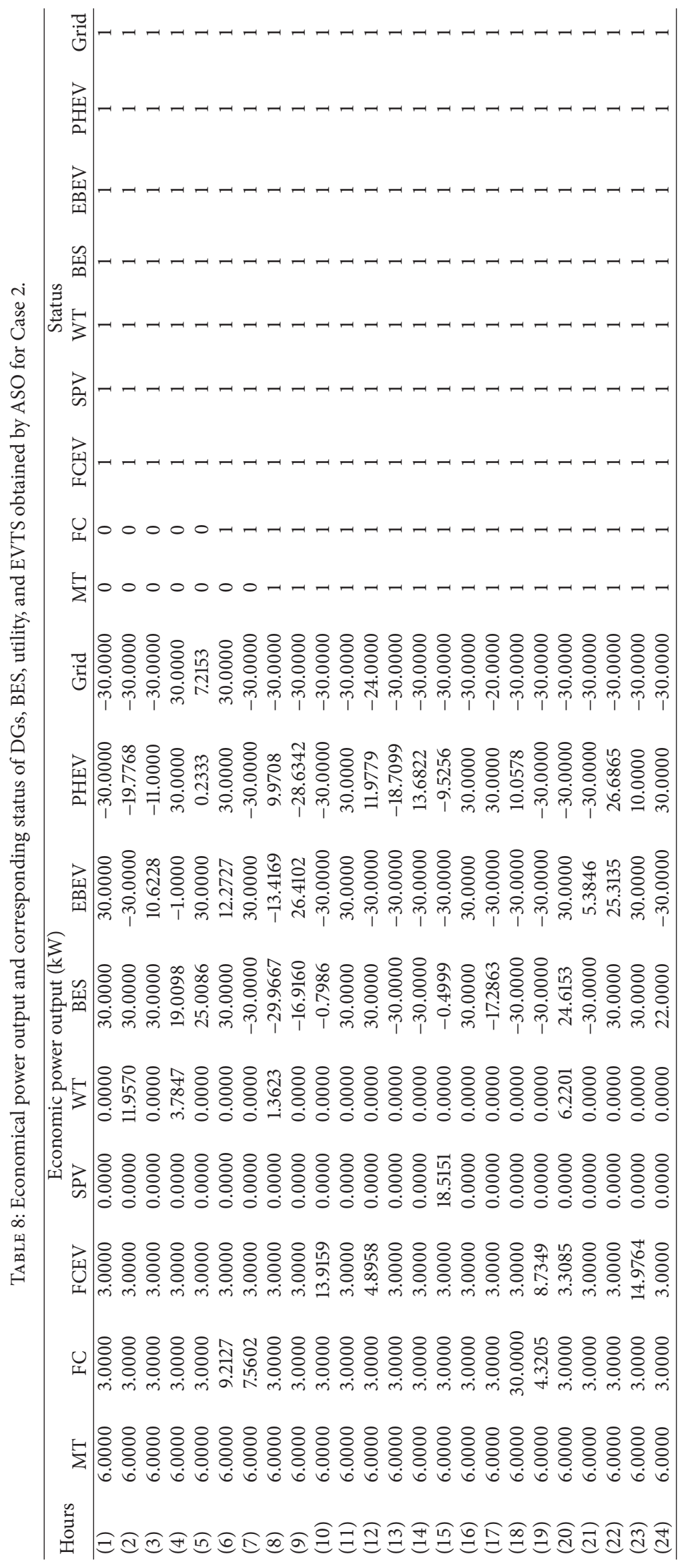


TABLE 9: Comparison of operation cost for Case 2 (30 trials), €ct/day.

\begin{tabular}{|c|c|c|c|c|c|c|c|c|}
\hline Methodology & $\begin{array}{c}\text { Best } \\
\text { solution }\end{array}$ & $\begin{array}{c}\text { Worst } \\
\text { solution }\end{array}$ & $\begin{array}{l}\text { Average } \\
\text { solution }\end{array}$ & $\begin{array}{c}\text { Number of hits to } \\
\text { optimal solution }\end{array}$ & $\begin{array}{r}\text { Standard } \\
\text { deviation }\end{array}$ & $\begin{array}{c}\text { Number of } \\
\text { trials }\end{array}$ & $\begin{array}{c}\text { Population } \\
\text { size }\end{array}$ & Iterations \\
\hline ASO & 1882.362 & 1983.628 & 1940.603 & 24 & 23.289825 & 30 & 50 & 250 \\
\hline SA & 1958.546 & 2140.723 & 2015.669 & 10 & 49.667268 & 30 & 50 & 250 \\
\hline GA & 1976.354 & 2042.508 & 2003.087 & 19 & 27.00037 & 30 & 50 & 250 \\
\hline $\mathrm{PSO}$ & 1970.121 & 2041.74 & 1994.255 & 18 & 31.20696 & 30 & 50 & 250 \\
\hline
\end{tabular}

TABLE 10: Optimized capacities of batteries in Case 1.

\begin{tabular}{lccccccccc}
\hline \multirow{2}{*}{ Methodology } & & Best & & \multicolumn{3}{c}{ Mean } & \multicolumn{3}{c}{ Worst } \\
& BES & BEV & PHEV & BES & BEV & PHEV & BES & BEV & PHEV \\
\hline ASO & 5 & 5 & 5 & 5 & 5 & 5 & 5 & 5 & 5.2772 \\
PSO & 5.01 & 5.0447 & 5.0377 & 5.1638 & 5.1343 & 5.2627 & 5.4759 & 5.6269 \\
GA & 5.0119 & 5.0232 & 5.0295 & 5.0748 & 5.1717 & 5.311 & 5.105 & 5.5354 & 5.6876 \\
SA & 5 & 5 & 5 & 5.0286 & 5.0921 & 5.079 & 5.0763 & 5.201 & 5.201 \\
\hline
\end{tabular}

TABLE 11: Optimized capacities of batteries in Case 2.

\begin{tabular}{lccccccccc}
\hline \multirow{2}{*}{ Methodology } & & Best & & \multicolumn{3}{c}{ Mean } & \multicolumn{3}{c}{ Worst } \\
& BES & BEV & PHEV & BES & BEV & PHEV & BES & BEV & PHEV \\
\hline ASO & 5 & 5 & 5 & 5 & 5 & 5 & 5 & 5 & 5.181 \\
PSO & 5.0118 & 5.0109 & 5.008 & 5.0582 & 5.5696 & 5.0402 & 6.2371 & 5.0747 \\
GA & 5.0363 & 5.0736 & 5.0135 & 5.253 & 5.4516 & 5.3123 & 5.5914 & 5.9732 & 5.6427 \\
RCSA & 5 & 5 & 5 & 5.1389 & 5.0601 & 5.0432 & 5.472 & 5.2969 & 5.1448 \\
\hline
\end{tabular}

SA: $\quad$ Simulated annealing

SMES: Superconducting magnetic energy storage

Std.: Standard deviation

TCPD: Total cost per day

Li-ion: Lithium ion

WT: Wind turbine.

\section{Nomenclature}

$i_{\mathrm{WT}}, i_{\mathrm{PV}}$ :

iter:

$S_{\text {near }}$ :

$S_{\text {far: }}:$

$T_{p}:$

$t p:$

$S_{\text {near }}^{\text {min }}, S_{\text {near }}^{\text {max }}$

$S_{\mathrm{far}}^{\min }, S_{\mathrm{far}}^{\max }:$

$S_{d}$ :

$P($ iter $)$ :

$D t$ :
Wind turbine (WT) and photovoltaic (PV) indices, respectively

Number of iterations for the

ASO

Sounds of nearby prey

Sounds of faraway prey

Threshold probability of finding prey

Probability of finding prey

The minimum and maximum audible sounds of nearby prey The minimum and maximum audible sounds of faraway prey Speed of shark

Position of shark in iteration iter Distance between prey and the previous position of shark.

\section{Constants}

$\operatorname{Bid}_{\mathrm{BES}, t}, \operatorname{Bid}_{\text {grid }, t}$, $\operatorname{Bid}_{\mathrm{FC}, t}, \operatorname{Bid}_{\mathrm{MT}, t}$,

$\operatorname{Bid}_{i_{\mathrm{WT}}, t}, \operatorname{Bid}_{i_{\mathrm{PV}}, t}$,

$\mathrm{Bid}_{\mathrm{FCEV}, t}$ :

$\mathrm{MC}_{\mathrm{BES}}, \mathrm{FX}_{\mathrm{BES}}$,

$\mathrm{MC}_{\mathrm{BEV}}, \mathrm{FX}_{\mathrm{BEV}}$,

$\mathrm{MC}_{\mathrm{PHEV}}, \mathrm{FX}_{\mathrm{PHEV}}$ :

IR:

LT:

max_iter:

$\mathrm{Sh}_{i}:$

$n:$

$f\left(\mathrm{Sh}_{i}\right)$ :

NT:

$\mathrm{OR}_{t}$ :

$\mathrm{OM}_{\mathrm{DG}}, \mathrm{OM}_{\mathrm{MT}}$, $\mathrm{OM}_{\mathrm{FC}}, \mathrm{OM}_{i_{\mathrm{WT}}}, \mathrm{OM}_{i_{\mathrm{PV}}}, \quad$ operation cost of DGs, MT, FC,

$\mathrm{OM}_{\mathrm{FCEV}}$ :
Bid of BES, utility, FC, MT, WT, $\mathrm{PV}$, and FCEV at time step $t$, respectively (€ $\mathrm{ct} / \mathrm{kW} \mathrm{h})$

Maintenance and fixed cost for BES, BEV, and PHEV, respectively (€ ct/kWh)

Interest rate for battery installation on loan

Installed batteries' lifetime (year)

Number of the maximum iterations for the proposed ASO $i$ th shark

Number of sharks

Function value of $i$ th shark Time horizon of operation (h) Generation reserve minutes (kW)

Constant maintenance and WT, PV, and FCEV, respectively, in $€ c t / k W h$ 


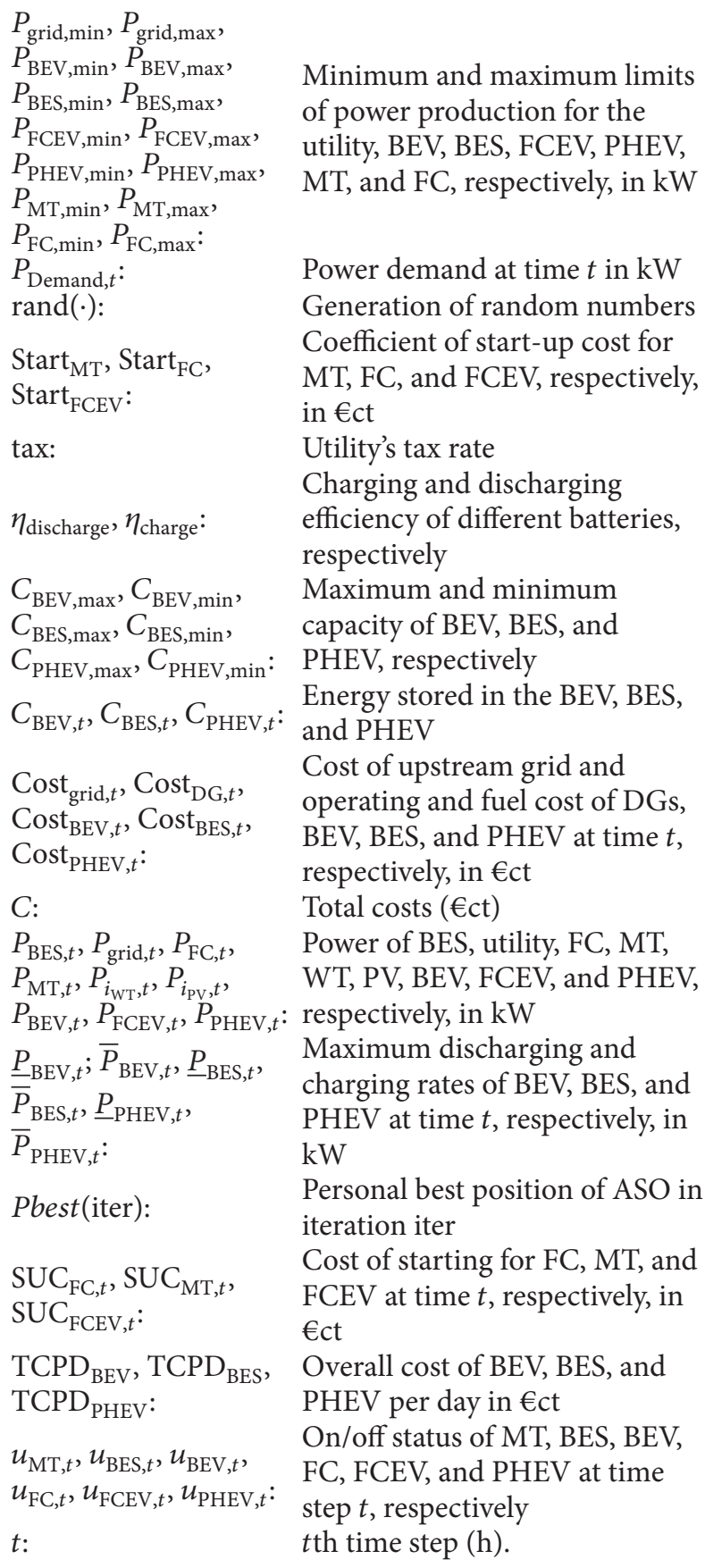

\section{Conflicts of Interest}

The authors declare that there are no conflicts of interest regarding the publication of this paper.

\section{References}

[1] X. Tan, Q. Li, and H. Wang, "Advances and trends of energy storage technology in Microgrid," International Journal of Electrical Power \& Energy Systems, vol. 44, no. 1, pp. 179-191, 2013.

[2] J. Corrêa, F. Farret, L. Canha, and M. Simões, IEEE Trans.Ind. Elects, vol. 51, article 1103, 2004.

[3] F. Jurado, "Fuzzy Logic Applied to the Inverter of a SOFC Power Plant," Fuel Cells, vol. 4, no. 4, pp. 378-387, 2004.
[4] F. Marechal, F. Palazzi, J. Godat, and D. Favrat, "Thermoeconomic modelling and optimisation of fuel cell systems," Fuel Cells, vol. 5, no. 1, pp. 5-24, 2005.

[5] G. Masters, Renewable and Efficient Electric Power Systems, John Wiley \& Sons Inc, Hoboken, NY, USA, 3rd edition, 2004.

[6] J. Mitra, "Reliability-based sizing of backup storage," IEEE Transactions on Power Systems, vol. 25, no. 2, pp. 1198-1199, 2010.

[7] O. Ekren and Y. Ekren Banu, "Size optimization of a PV/wind hybrid energy conversion system with battery storage using simulated annealing," Applied Energy, vol. 87, no. 2, pp. 592-598, 2010.

[8] M. Mohammadi, S. H. Hosseinian, and G. B. Gharehpetian, "GA-based optimal sizing of microgrid and DG units under pool and hybrid electricity markets," International Journal of Electrical Power \& Energy Systems, vol. 35, no. 1, pp. 83-92, 2012.

[9] B. Bahmani-Firouzi and R. Azizipanah-Abarghooee, "Optimal sizing of battery energy storage for Micro-Grid operation management using a new improved bat algorithm," Electr. Power Energy Syst, vol. 56, no. 1, pp. 42-54, 2014.

[10] S. Chakraborty, M. G. Weiss, M. D. Weiss, and M. G. Simoes, "Distributed intelligent energy management system for a singlephase high frequency AC microgrid," IEEE Transactions on Industrial Electronics, vol. 54, no. 1, pp. 97-109, 2007.

[11] E. Sortomme and M. A. El-Sharkawi, "Optimal power flow for a system of microgrids with controllable loads and battery storage," in proceedings of the IEEE/PES Power Systems Conf. and Exposition, pp. 1-5, 2009.

[12] T. Niknam, A. Kavousifard, S. Tabatabaei et al., "Optimal operation management of fuel cell /wind / photovoltaic power sources connected to distribution networks," Journal of Power Sources, vol. 196, no. 20, pp. 8881-8896, 2011.

[13] S. Sharma, S. Bhattacharjee, and A. Bhattacharya, "Grey wolf optimisation for optimal sizing of battery energy storage device to minimise operation cost of microgrid," in IET Generation, Transmission \& Distribution, vol. 10, pp. 625-637, 2016.

[14] F. Laureri, L. Puliga, M. Robba, F. Delfino, and G. O. Bultò, "An optimization model for the integration of electric vehicles and smart grids: Problem definition and experimental validation," in proceedings of the IEEE International Smart Cities Conference (ISC2), pp. 1-6, Trento, Italy, 2016.

[15] D. Bai, H. Cao, and L. Wang, "Research and simulation of V2G technology in micro grid," in proceedings of the China International Conference on Electricity Distribution (CICED), pp. 1-5, Xi'an, China, 2016.

[16] G. Chen, Q. Cheng, H. Wang, M. Li, C. Xu, and L. Deng, "Study on bi-directional energy transfer of EV charging station on micro-grid operation," in Proceeding of the 11th World Congress on Intelligent Control and Automation, pp. 5517-5522, Shenyang, China, 2014.

[17] S. J. Gunter, K. K. Afridi, and D. J. Perreault, "Optimal design of grid-connected pev charging systems with integrated distributed resources," IEEE Transactions on Smart Grid, vol. 4, no. 2, pp. 956-967, 2013.

[18] S. X. Chen, H. B. Gooi, and M. Q. Wang, "Sizing of energy storage for microgrids," IEEE Trans Smart Grid, vol. 3, pp. 142151, 2012.

[19] M. Basu, "Hybridization of bee colony optimization and sequential quadratic programming for dynamic economic dispatch," International Journal of Electrical Power \& Energy Systems, vol. 44, pp. 591-596, 2013. 
[20] R. Azizipanah-Abarghooee, "A new hybrid bacterial foraging and simplified swarm optimization algorithm for practical optimal dynamic load dispatch," Int J Electr Power Energy Syst, vol. 49, pp. 414-429, 2013.

[21] E. Bunting, Sea World Book of Sharks, Harcourt, Brace, Janovich, NY, USA, 1989.

[22] Y. Wang, B. Li, T. Weise, J. Wang, B. Yuan, and Q. Tian, "Selfadaptive learning based particle swarm optimization," Information Sciences, vol. 181, pp. 4515-4538, 2011.

[23] F. Van den Bergh and A. Engelbrecht, "A study of particle swarm optimization particle trajectories," Information Sciences, vol. 176, pp. 937-971, 2006.

[24] A. Anvari Moghaddam, A. Seifi, T. Niknam, and M. R. Alizadeh Pahlavani, "Multiobjective operation management of a renewable MG (micro-grid) with backup micro-turbine/fuel cell/battery hybrid power source," Energy, vol. 36, pp. 64906507, 2011.

[25] T. Niknam and F. Golestaneh, "Probabilistic multiobjective operation management of microgrids with hydrogen storage and polymer exchange fuel cell power plants," Fuel Cells, vol. 12, pp. 809-826, 2012.

[26] X. Tan, Q. Li, and H. Wang, "Advances and trends of energy storage technology in Microgrid," International Journal of Electrical Power \& Energy Systems, vol. 44, pp. 179-191, 2013.

[27] W. Al-Saedi, S. W. Lachowicz, D. Habibi, and O. Bass, "Power quality enhancement in autonomous microgrid operation using particle swarm optimization," International Journal of Electrical Power \& Energy Systems, vol. 42, pp. 139-149, 2013.

[28] W. Gu, Z. Wu, R. Bo, W. Liu, G. Zhou, W. Chen et al., "Modeling, planning and optimal energy management of combined cooling, heating and power microgrid: a review," Int J Electr Power Energy Syst, vol. 54, pp. 26-37, 2014.

[29] R. Azizipanah-Abarghooee, T. Niknam, A. Roosta, A. R. Malkpour, and M. Zare, "Probabilistic multiobjective wind-thermal economic emission dispatch based on point estimated method," Energy, vol. 37, pp. 322-335, 2012.

[30] T. Niknam, R. Azizipanah-Abarghooee, and M. R. Narimani, "An efficient scenario based stochastic programming framework for multi-objective optimal microgrid operation," Applied Energy, vol. 99, pp. 455-470, 2012.

[31] R. Ashok Bakkiyaraj and N. Kumarappan, "Optimal reliability planning for a composite electric power system based on Monte Carlo simulation using particle swarm optimization," International Journal of Electrical Power \& Energy Systems, vol. 47, pp. 109-116, 2013.

[32] T. Niknam, R. Azizipanah-Abarghooee, M. Zare, and B. Bahmani-Firouzi, "Reserve constrained dynamic environmental/economic dispatch: a new multiobjective self-adaptive learning bat algorithm," IEEE Systems Journal, vol. 7, pp. 763776, 2013. 


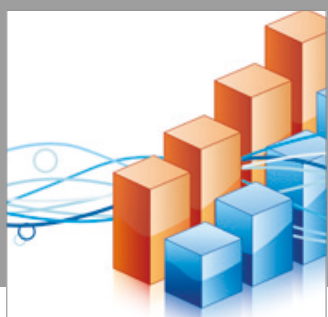

Advances in

Operations Research

vatersals

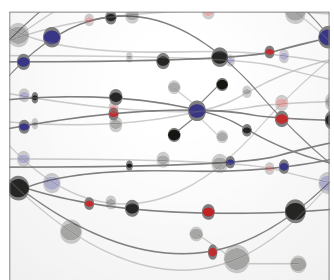

\section{The Scientific} World Journal
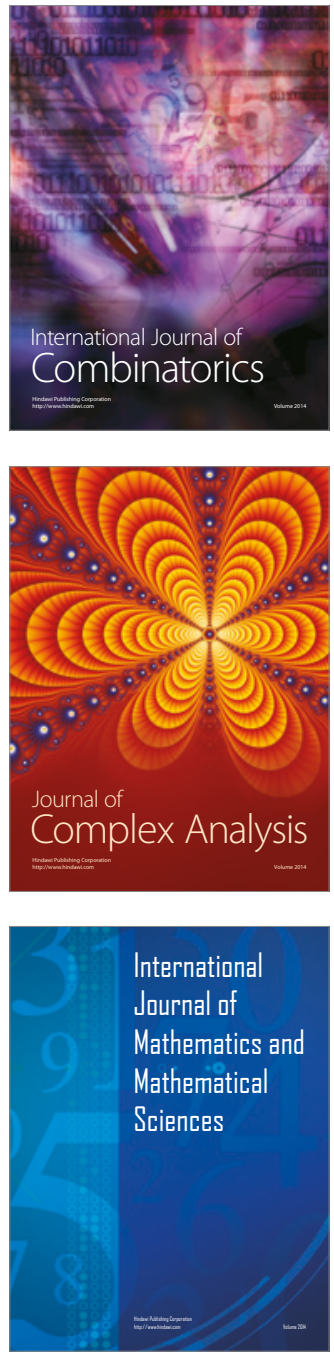
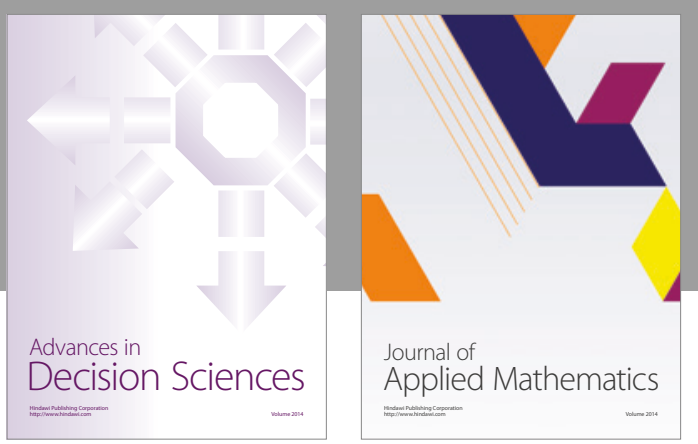

Algebra

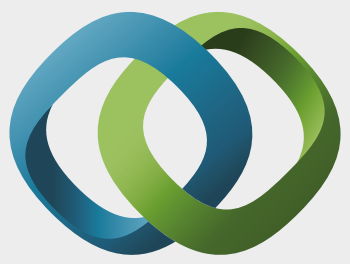

\section{Hindawi}

Submit your manuscripts at

https://www.hindawi.com
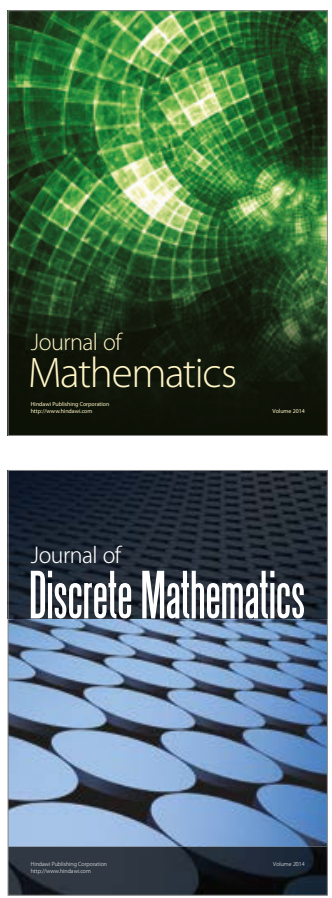

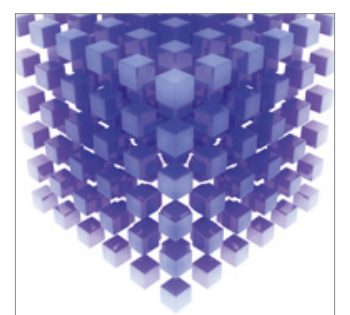

Mathematical Problems in Engineering
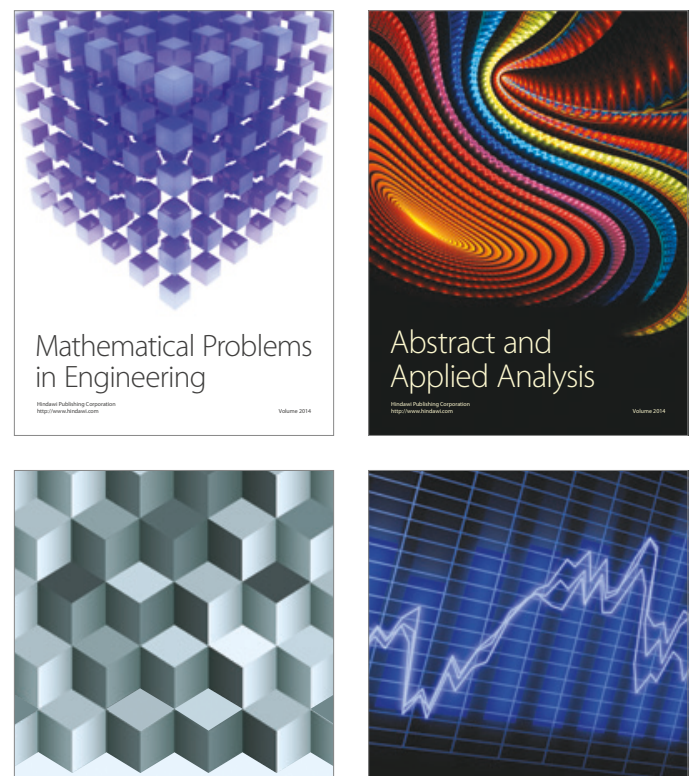

Journal of

Function Spaces

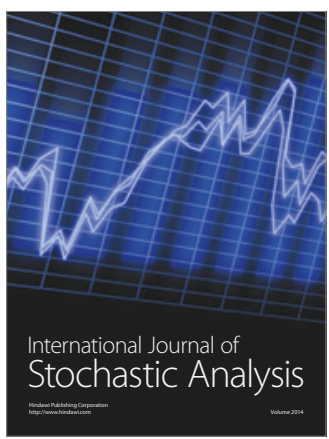

Probability and Statistics
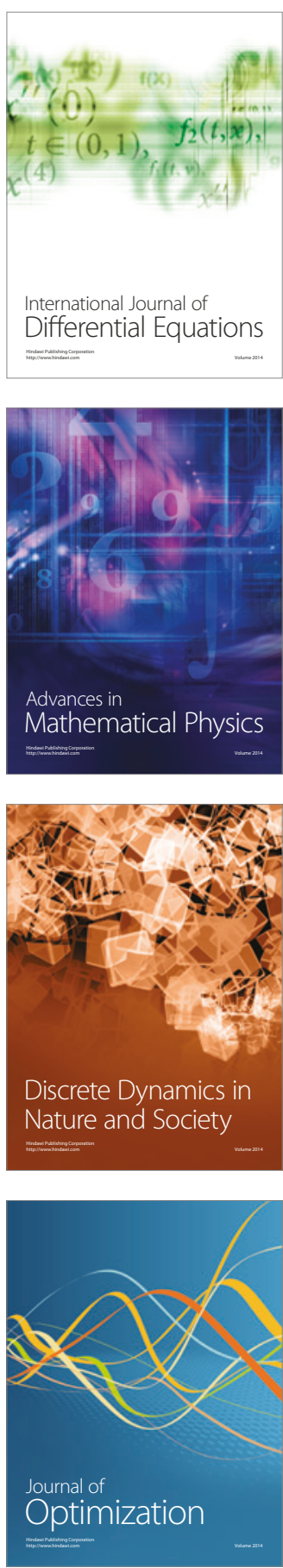